\title{
Strain Background Influences Neurotoxicity and Behavioral Abnormalities in Mice Expressing the Tetracycline Transactivator
}

\author{
Harry J. Han, ${ }^{1,10}$ Carolyn C. Allen, ${ }^{1}$ Christie M. Buchovecky ${ }^{4}$ Michael J. Yetman, ${ }^{1}$ Heather A. Born, ${ }^{1}$ Miguel A. Marin, ${ }^{1}$ \\ Shaefali P. Rodgers, ${ }^{1}$ Bryan J. Song, ${ }^{1}$ Hui-Chen Lu, ${ }^{1,5,9}$ Monica J. Justice, ${ }^{4,6,7}$ Frank J. Probst, ${ }^{4}$ \\ and Joanna L. Jankowsky ${ }^{1,2,3,8}$ \\ Departments of ${ }^{1}$ Neuroscience, ${ }^{2}$ Neurology, ${ }^{3}$ Neurosurgery, ${ }^{4}$ Molecular and Human Genetics, ${ }^{5}$ Pediatrics, and ${ }^{6}$ Molecular Physiology and Biophysics, and \\ the ${ }^{7}$ Dan L. Duncan Cancer Center, the ${ }^{8}$ Huffington Center on Aging, and ${ }^{9}$ The Cain Foundation Laboratories, Baylor College of Medicine, Houston, Texas \\ 77030, and ${ }^{10}$ Department of Biochemistry and Cell Biology, Rice University, Houston, Texas 77005
}

The tet-off system has been widely used to create transgenic models of neurological disorders including Alzheimer's, Parkinson's, Huntington's, and prion disease. The utility of this system lies in the assumption that the tetracycline transactivator (TTA) acts as an inert control element and does not contribute to phenotypes under study. Here we report that neuronal expression of TTA can affect hippocampal cytoarchitecture and behavior in a strain-dependent manner. While studying neurodegeneration in two tet-off Alzheimer's disease models, we unexpectedly discovered neuronal loss within the dentate gyrus of single transgenic TTA controls. Granule neurons appeared most sensitive to TTA exposure during postnatal development, and doxycycline treatment during this period was neuroprotective. TTA-induced degeneration could be rescued by moving the transgene onto a congenic C57BL/6J background and recurred on reintroduction of either CBA or $\mathrm{C} 3 \mathrm{H} / \mathrm{He}$ backgrounds. Quantitative trait analysis of $\mathrm{B} 6 \mathrm{C} 3 \mathrm{~F} 2$ TTA mice identified a region on Chromosome 14 that contains a major modifier of the neurodegenerative phenotype. Although $\mathrm{B} 6$ mice were resistant to degeneration, they were not ideal for cognitive testing. F1 offspring of TTA C57BL/6J and 129X1/SvJ, FVB/NJ, or DBA/1J showed improved spatial learning, but TTA expression caused subtle differences in contextual fear conditioning on two of these backgrounds, indicating that strain and genotype can interact independently under different behavioral settings. All model systems have limitations that should be recognized and mitigated where possible; our findings stress the importance of mapping the effects caused by TTA alone when working with tet-off models.

\section{Introduction}

The tetracycline transactivator system offers unparalleled flexibility to spatially restrict and temporally control transgenes in vivo using a readily available, systemically delivered drug. The system is based on an artificial fusion protein called the tetracycline transactivator (TTA), which combines the DNA- and tetracycline-binding domains of the Escherichia coli Tn10 tetracycline repressor with the transcriptional activation domain of the herpes simplex virion protein 16 (VP16) (Gossen and Bujard, 1992). Transgenic expression of TTA is used to activate a second

\footnotetext{
Received Feb. 23, 2012; revised May 24, 2012; accepted June 13, 2012.

Author contributions: H.J.H. and J.L.J. designed research; H.J.H., C.C.A., C.M.B., M.J.Y., H.A.B., M.A.M., S.P.R., B.J.S., and J.L.J. performed research; H.-C.L., M.J.J., and F.J.P. contributed unpublished reagents/analytic tools; H.J.H., C.C.A., C.M.B., M.J.Y., H.A.B., F.J.P., and J.L.J. analyzed data; H.J.H. and J.L.J. wrote the paper.

This work was supported by NIH Grants OD001734 and AG026144 to J.L.J. S.P.R. and H.A.B. were supported by NIH Grant T32-AG000183, and C.M.B. by Autism Science Foundation predoctoral fellowship 11-1015. We thank Mark Mayford for sharing animals from his colony; Paul Overbeek, Mark West, and Evelin Schaeffer for sharing unpublished data; Sidali Benazouz, Beth Olsen, and Anna Gumpel for animal care; Tara Paton for SNP microarray analysis; Paul Overbeek for critical reading of the manuscript; and the Jankowsky lab for helpful discussion and advice. The authors declare no financial conflicts of interest.

Correspondence should be addressed to Joanna L. Jankowsky, Department of Neuroscience, BCM295, Baylor College of Medicine, One Baylor Plaza, Houston, TX 77030. E-mail: jankowsk@bcm.edu.

DOI:10.1523/JNEUROSCI.0893-12.2012

Copyright $\odot 2012$ the authors $\quad 0270-6474 / 12 / 3210574-13 \$ 15.00 / 0$
}

transgene of interest that is placed downstream of the tetracycline response element (TRE), composed of the tet-operator and a minimal promoter. Exposure to tetracycline, or its more stable analog doxycycline, causes a conformational change in TTA that inhibits binding to TRE and in turn stops expression of the TREcontrolled transgene, allowing external temporal control of transgene expression (Gossen and Bujard, 1992; Furth et al., 1994).

Transgenic (Tg) lines in which TTA expression is restricted to the CNS have become valuable tools in neuroscience research. One line in particular, expressing TTA under the CaMKII $\alpha$ promoter (Mayford et al., 1996), has been widely used in models of neurological disorders (Yamamoto et al., 2000; Cruz et al., 2003; Jankowsky et al., 2005; Santacruz et al., 2005; Alvarez-Saavedra et al., 2007; Muyllaert et al., 2008; Pletnikov et al., 2008; Wang et al., 2008). The CaMKII $\alpha$-TTA transgenic line has been especially useful in modeling Alzheimer's disease, where it has been used to drive expression of amyloid precursor protein (APP) and microtubule-associated tau protein (Tau) in forebrain areas affected by the disease (Jankowsky et al., 2005; Ramsden et al., 2005; Santacruz et al., 2005). The rTg4510 Tau mouse exhibits robust, progressive neurodegeneration characteristic of Alzheimer's disease, losing $60 \%$ of CA1 neurons by $5-6$ months of age (Ramsden 
et al., 2005; Santacruz et al., 2005). The severity of neuronal loss in this line was surprising given the absence of overt atrophy in other tau transgenic mice created with standard noncontrollable promoters (Lewis et al., 2000; Götz et al., 2001), and has generally been attributed to the high level of transgene expression possible with the TTA system.

We hypothesized that the high levels of transgene expression in the tet-off APP model might similarly allow us to demonstrate $\mathrm{A} \beta$-related neurodegeneration despite mixed reports of neuronal loss in standard APP transgenic lines (Irizarry et al., 1997a,b; Calhoun et al., 1998). While investigating this hypothesis, we unexpectedly observed hippocampal granule cell loss in single transgenic controls only expressing TTA. We discovered that the genetic strain background on which TTA is expressed dramatically influenced neurodegeneration caused by TTA protein. We also found that TTA expression can affect cognitive performance in several commonly used behavioral tasks, again in a straindependent manner. Because many groups, including ours, continue to use tet-off models to study neurological disorders, we undertook a series of systematic experiments to better characterize the interaction between strain background, TTA-induced neuronal loss, and behavior so that potential deficits could be identified and controlled.

\section{Materials and Methods}

Generation and maintenance of transgenic mouse lines

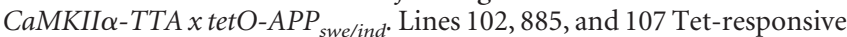
APP mice were initially generated on an C57BL/6 $\times$ C3H/He (B6C3) F2 hybrid background (Jankowsky et al., 2005) and then mated with CaMKII $\alpha$-TTA line B purchased from Jackson Laboratories on a mixed C57BL/6 × CBA (B6CBA) background [strain \#3010 (Mayford et al., 1996)] to generate TTA/APP mice on a mixed B6/C3/CBA background. The TTA strain \#3010 was deposited at The Jackson Laboratory on a mixed B6CBA background in 1998 and maintained by sibling mating until 2001 when it was cryopreserved. Our original TTA animals were purchased from The Jackson Laboratory in 2001 just before cryopreservation. Since being reestablished in 2006, the currently available \#3010 line was backcrossed twice onto the C57BL/6J (B6) background before continuing with sibling mating, and so is now two generations closer to being congenic on B6 than it was at the start of our study.

The TTA/APP bigenic model was maintained for several years through two breeding strategies: some matings used double-transgenic B6/C3/ CBA TTA/APP males with B6C3 F1 females from The Jackson Laboratory (strain \#100010); others used single transgenic B6/C3/CBA males with single-transgenic $\mathrm{C} 3 / \mathrm{B} 6 / \mathrm{CBA}$ females (i.e., TTA male with APP female). Animals harvested on a B6/C3/CBA hybrid background were taken from this colony. In 2005, we began backcrossing each transgene onto a B6 background by mating APP and TTA single-transgenic animals to B6 mates (The Jackson Laboratory strain \#664) for >20 generations. The Y chromosome was made congenic by including at least one generation in which female APP and TTA transgenic animals were mated with B6 males. Animals harvested on the B6 congenic background were taken from this colony at backcross generations N19-N24. The tetO-APP line 102 was cryopreserved by The Jackson Laboratory at B6 backcross generation N11 and is available through the Mouse Mutant Regional Resource Center (MMRRC) as strain 34845. TetO-APP lines 107 and 885 were similarly backcrossed and are available at MMRRC as strain \#34846 and \#34844. The CaMKII $\alpha$-TTA line was independently made congenic on B6 and deposited with The Jackson Laboratory as strain \#7004.

CaMKII $\alpha-T T A / T e t O-T_{P u} u_{P 301 L}(r T g 4510)$. Single transgenic CaMKII $\alpha$ TTA on a $129 / \mathrm{Sv}$ background and TetO-Tau $\mathrm{P}_{\mathrm{P} 301 \mathrm{~L}}$ mice on a FVB/N background (Santacruz et al., 2005) were obtained from Drs. Michael Hutton (Mayo Clinic, Jacksonville, FL) and Karen Ashe (University of Minnesota, Minneapolis, Minnesota). Each was then mated with animals expressing the mutant Wallerian Slow gene on a C57BL/6 background $\left(\mathrm{Wld}^{\mathrm{S}}\right.$ ) (Lyon et al., 1993) to generate bigenic TTA/Wld ${ }^{\mathrm{S}}$ and TetO$\mathrm{Tau}_{\mathrm{P} 301 \mathrm{~L}} / \mathrm{Wld}^{\mathrm{S}}$ offspring on a mixed B6/129/FVB background. Bigenic animals were then intercrossed to obtain double-transgenic TTA/TetO$\mathrm{Tau}_{\mathrm{P} 301 \mathrm{~L}}$ on this mixed background (Ljungberg et al., 2012). Mice were genotyped to ensure that none of the animals used in this study carried the Wld ${ }^{\mathrm{s}}$ mutation.

CaMKII $\alpha$-TTA on F1, F2, and intermediate backgrounds. Congenic CaMKII $\alpha$-TTA B6 N22 males were mated with wild-type C57BL/6J, $\mathrm{C} 3 \mathrm{H} / \mathrm{HeJ}, \mathrm{CBA} / \mathrm{J}, 129 \mathrm{X} 1 / \mathrm{SvJ}, \mathrm{DBA} / 1 \mathrm{~J}$, or FVB/NJ females (The Jackson Laboratory stocks \#664, \#659, \#656, \#691, \#670, or \#1800, respectively) to generate $\mathrm{B} 6$ congenic and $\mathrm{F} 1$ offspring for comparison. TTA transgenic $\mathrm{B} 6 \mathrm{C} 3 \mathrm{~F} 1$ males were further used to probe the effect of modifying the $\mathrm{C} 3$ and CBA content by mating with (1) wild-type $\mathrm{C} 3 \mathrm{H} / \mathrm{HeJ}$ females to generate progeny deriving on average $75 \%$ of its genetic material from the $\mathrm{C} 3$ background, (2) wild-type CBA/J females to generate animals on a mixed 50\% CBA/25\% C3/25\% B6 background, or (3) wild-type B6C3 F1 female siblings to generate B6C3 F2 offspring.

Mice were housed together in groups of two to four under a $14 \mathrm{~h} / 10 \mathrm{~h}$ light/dark cycle with lights on at 0600 . All experiments were conducted in accordance with the National Institute of Health's Guide for the Care and Use of Laboratory Animals and were approved by the Institutional Animal Care and Use Committees at Baylor College of Medicine and at the California Institute of Technology.

\section{Doxycycline treatment}

Doxycycline (dox) was administered through the chow, formulated to contain either $200 \mathrm{mg} / \mathrm{kg}$ antibiotic for animals treated continuously throughout life (BioServ \#S3888), or $50 \mathrm{mg} / \mathrm{kg}$ antibiotic for animals treated during postnatal development (Purina Mills Test Diet \#5SBA). Dosing was matched to the sensitivity of the responder line, with tetOAPP Lines 107 and 885 requiring a higher concentration of dox to maximally suppress the transgene than tetO-APP Line 102 (J.L.J., H.A.B., unpublished results). Lifelong dox treatment began in utero by feeding breeding trios medicated chow with offspring maintained on the same diet after weaning. Dox treatment during postnatal development began after birth by placing the nursing mother on medicated chow $1-3 \mathrm{~d}$ after delivery. Treatment was continued until 6 weeks of age by maintaining the pups on dox chow for 3 weeks after weaning.

\section{Tissue preparation and cresyl violet staining}

TTA/APP Line 102. Adult mice on the mixed C3/B6/CBA and congenic B6 backgrounds were killed by sodium pentobarbital overdose at ages ranging from 2 to 12 months $(n=3$ per genotype at each age) and transcardially perfused with cold PBS containing $10 \mathrm{U} / \mathrm{ml}$ heparin, followed with cold $4 \%$ paraformaldehyde (PFA) in $1 \times \mathrm{PBS} \mathrm{pH}$ 7.4. Brains were removed and postfixed in $4 \% \mathrm{PFA}$ overnight at $4^{\circ} \mathrm{C}$. Two-week-old C3/B6/CBA animals ( $n=3-5$ per genotype) were killed using $\mathrm{CO}_{2}$ inhalation and brains were removed and fixed by immersion in $4 \%$ PFA/ $1 \times \mathrm{PBS}$ for $48 \mathrm{~h}$ overnight at $4^{\circ} \mathrm{C}$. Animals on F1, F2, and intermediate backgrounds were killed at 3 months of age using $\mathrm{CO}_{2}$ inhalation. Brains were fixed by immersion in $4 \% \mathrm{PFA} / 1 \times \mathrm{PBS}$ for $48 \mathrm{~h}$ overnight at $4^{\circ} \mathrm{C}$ ( $n=6-14$ per genotype for $\mathrm{F} 1$ and intermediate backgrounds, $n=20$ per genotype for B6C3 F2, each group was approximately balanced for gender). Samples from all time points were stored in $1 \times \mathrm{PBS} / 0.1 \% \mathrm{PFA} /$ $0.1 \% \mathrm{NaN}_{3}$ until processing.

Brains were cryoprotected by overnight immersion in $30 \%$ sucrose/ $1 \times \mathrm{PBS}$ at $4^{\circ} \mathrm{C}$, sectioned at $35 \mu \mathrm{m}$ in the sagittal plane using a freezing sliding microtome, then stored in cryoprotectant $(0.1 \mathrm{M}$ phosphate buffer, $30 \%$ ethylene glycol, $25 \%$ glycerol) at $-20^{\circ} \mathrm{C}$ until staining. For cresyl violet staining, sections were thoroughly washed in $1 \times \mathrm{TBS}$ before being mounted on Superfrost Plus slides (Fisher Scientific) and dried overnight. Slides were defatted through alcohols and xylene, rehydrated, and stained with $0.1 \%$ cresyl violet acetate (Sigma-Aldrich \#860980 in $0.25 \%$ glacial acetic acid). Sections were dehydrated through alcohols and xylene and coverslipped with Permount (Fisher Scientific).

TTA/APP Lines 107 and 885. Animals were killed at 17-24 months of age using $\mathrm{CO}_{2}$ inhalation ( $n=4-6$ per genotype). Brains were fixed by immersion in $4 \% \mathrm{PFA} / 1 \times \mathrm{PBS}$ for $48 \mathrm{~h}$ overnight at $4^{\circ} \mathrm{C}$ then dehydrated and embedded in paraffin. Sagittal sections were cut at $10 \mu \mathrm{m}$, mounted onto Superfrost Plus slides, deparaffinized, stained with cresyl violet, and dehydrated before being coverslipped with Permount. 
$r \operatorname{Tg} 4510$. Mice at 4.5, 8 and 12 months of age were anesthetized with a mixture of ketamine/xylazine and transcardially perfused with ice-cold PBS pH 7.4, followed by $4 \%$ PFA/ $1 \times$ PBS. Brains were postfixed in $4 \%$ PFA overnight, then embedded in paraffin. Sagittal sections were cut at 6 $\mu \mathrm{m}$, and processed as described for Line 107.

\section{Dentate gyrus analysis}

The width of the dentate gyrus was measured from cresyl violet-stained sections under brightfield illumination on an AxioImager Z1 microscope using the interactive Measure feature of Axiovision 4.7 (Carl Zeiss). Three sections from each animal, at $\sim 0.60,1.20$, and $1.92 \mathrm{~mm}$ lateral from midline (Franklin and Paxinos, 2008), were used for analysis. Two measurements, perpendicular to the main axis of the cell layer, were made on each blade of the gyrus for a total of four measurements per section. Values were averaged for each animal and used to generate group means. Measurements from single-transgenic tetO-APP Line 102 animals were not significantly different from non- $\mathrm{Tg}$ (NTG) animals, and so were collapsed into a single control group. A score of zero was assigned if the dentate gyrus was too disorganized to measure.

To confirm that width measurements of the dentate gyrus reflected the number of granule cells remaining and not simply a reduction in cell body size, we performed cell counts within fixed-dimension fields of the granule cell layer. Three sections from each animal at approximately the same sagittal planes used for width measurements were selected for analysis. DAPI stain was used to fluorescently label cell nuclei, followed by structured illumination imaging with an ApoTome optical sectioning device (Carl Zeiss). One or two nonoverlapping fields of view were imaged at $20 \times$ magnification for each blade of the dentate gyrus, with the long axis of the frame aligned parallel to the cell body layer. At this magnification, each field spanned 450 linear micrometers of the granule cell layer. A single optical section of $1.4 \mu \mathrm{m}$ in depth was collected from each field, and the individual nuclei within the granule cell layer counted manually using the interactive Count feature of AxioVision 4.7. The width of the granule cell layer was also measured for each field of view so that the relationship between width and cell number could be analyzed by field and averaged by animal.

\section{Behavioral assays}

Young adult congenic B6 and F1 animals were tested at 2 months of age in open-field, Morris water maze, and contextual fear conditioning. Animals were handled for $2 \mathrm{~d}$ before the start of behavioral training. Openfield assessment began on day 1 , followed by Morris water maze testing on days $2-7$. After a 2-3 d recovery period, animals were trained for contextual fear conditioning and retention was tested $24 \mathrm{~h}$ later. Each cohort had $n=10-14$ animals per genotype balanced for gender.

\section{Open-field assessment}

Open-field assessment was conducted in open-top white acrylic boxes $(18 \times 18 \times 9$ in $)$ in a room lit with indirect white light. Animals were allowed to explore the arena freely for $30 \mathrm{~min}$. Movement was recorded and analyzed using the ANY-Maze Video Tracking System (Stoelting). For analysis, the box was divided into a center zone and a perimeter, with the center defined as a square occupying $1 / 3$ of the arena. The total path length was calculated, as was the proportion of this distance spent in the center zone.

\section{Morris water maze}

The Morris water maze (MWM) testing began with $1 \mathrm{~d}$ of training in a straight swim channel, followed by $5 \mathrm{~d}$ of acquisition training and recall testing in the full circular pool. Water was made opaque with nontoxic white paint and the temperature was maintained between 21 and $23^{\circ} \mathrm{C}$. The room was lit with indirect white light. Swim path was videotaped and tracked using the ANY-Maze Video Tracking System.

The straight swim task was used to introduce animals to the task. The channel consisted of a $6.5 \times 42 \times 22$ inches rectangular lane placed in the water tank to restrict movement within a fixed straight path. A white curtain was drawn around the tank to minimize external visual cues. Mice were allowed $60 \mathrm{~s}$ to reach a submerged platform on the opposite end of the channel and remain on the platform for $15 \mathrm{~s}$. If the animal failed to reach the platform, it was gently guided to the location. Each mouse underwent a total of eight straight swim trials with an intertrial interval of $20 \mathrm{~min}$.

MWM was conducted in a 23-inch-tall, 48-inch-diameter circular tank filled with opaque water to within 8 inches of the top. Large, highcontrast objects, which served as distal cues, were placed on the walls surrounding the tank. A square platform $10 \times 10 \mathrm{~cm}$ was located $0.5 \mathrm{~cm}$ beneath the water surface, halfway between the wall and the center of the tank, in the northeast quadrant of the tank. For each trial, animals were placed semirandomly at one of the four cardinal points of the tank and given $60 \mathrm{~s}$ to locate the submerged platform. If the animal failed to locate the platform in the allotted time, it was gently guided to the platform. Animals were allowed to remain on the platform for $15 \mathrm{~s}$. Each animal received four trials per day with a $20 \mathrm{~min}$ intertrial interval.

At the end of each four-trial training session, the platform was removed for an immediate probe test. Animals were placed into the tank at pseudorandom positions halfway between the cardinal points (SW, NW, $\mathrm{SE}$ ) and given $45 \mathrm{~s}$ to explore the tank. To deter extinction learning, the platform was returned to its original position at the end of each $45 \mathrm{~s}$ probe, and animals were then allowed to locate the hidden platform and remain there for $15 \mathrm{~s}$. Additionally, animals received a long-term memory probe test before the start of each daily training session, $\sim 24 \mathrm{~h}$ after the previous day's training session. Long-term memory probe trials began of day 2 of water maze and continued throughout the remaining testing sessions. As with the immediate probe, the platform was returned to the tank after $45 \mathrm{~s}$ to avoid extinction.

On day 6 of MWM, animals underwent the final long-term probe trial and were then examined for sensorimotor function using a cued platform version of the water maze. A white curtain was drawn around the tank to hide distal visual cues and the platform was labeled with a tall striped rod protruding from the water. Animals were placed in the opposite quadrant and given $45 \mathrm{~s}$ to find the platform. A total of eight trials were conducted, during which the platform was moved pseudorandomly to a new quadrant between each trial.

\section{Contextual fear conditioning}

Contextual fear conditioning was performed using a Near Infrared Video Fear Conditioning system (Med Associates). Conditioning chambers consisted of a $10 \times 11.5$ inch stainless steel grid floor and clear Plexiglas walls. Chambers were placed within larger sound-attenuating boxes and indirectly lit from above. Movement was tracked using a video camera mounted inside the sound-attenuating box and analyzed using Video Freeze software (Med Associates). Motion threshold was set to 19 arbitrary units and the minimum freeze duration was set to $1 \mathrm{~s}$. Between each animal, the steel grid floor and drop pans were washed with water and the chambers were cleaned with ethanol.

During conditioning, each animal was placed into the chamber and allowed to explore freely for $5 \mathrm{~min}$ before receiving a $2 \mathrm{~s} 0.8 \mathrm{~mA}$ foot shock. Mice remained in the chamber for 1 min postshock before being returned to their home cage. Twenty-four hours later, animals were returned to the same chamber for $5 \mathrm{~min}$ and the duration of freezing was measured. Animals were harvested for histological analysis 1-2 wk later.

\section{DNA isolation and genetic mapping}

Genomic DNA for single nucleotide polymorphisms (SNP) analysis was isolated from tail biopsies of B6C3 F2 TTA transgenic mice $(n=20)$, B6C3 F1 NTG $(n=1)$, and B6 NTG controls $(n=1)$. F2 animals for genetic analyses were generated from two independent breeding trios, each composed of one B6C3 F1 TTA transgenic male and two B6C3 NTG females. Offspring were sampled from both trios so that animals used for analysis came from all four possible parentages. Tails were collected immediately before death and stored at $-80^{\circ} \mathrm{C}$ until digestion. DNA was isolated by proteinase $\mathrm{K}$ digestion followed by phenol-chloroform extraction and isopropanol precipitation (Nagy, 2003), and finally diluted to a concentration of $75 \mathrm{ng} / \mu \mathrm{l}$ in $10 \mathrm{~mm}$ Tris/1 mm EDTA buffer. Whole genome SNP analysis was performed using the Illumina GoldenGate Mouse Medium Density Linkage Array for 1449 SNPs in the array across the 19 autosomes and X chromosome, yielding 916 informative SNPs. Statistical analysis for linkage was performed using R/qtl software (version 1.21-2; www.rqtl.org) with linkage analysis expressed as logarithm 

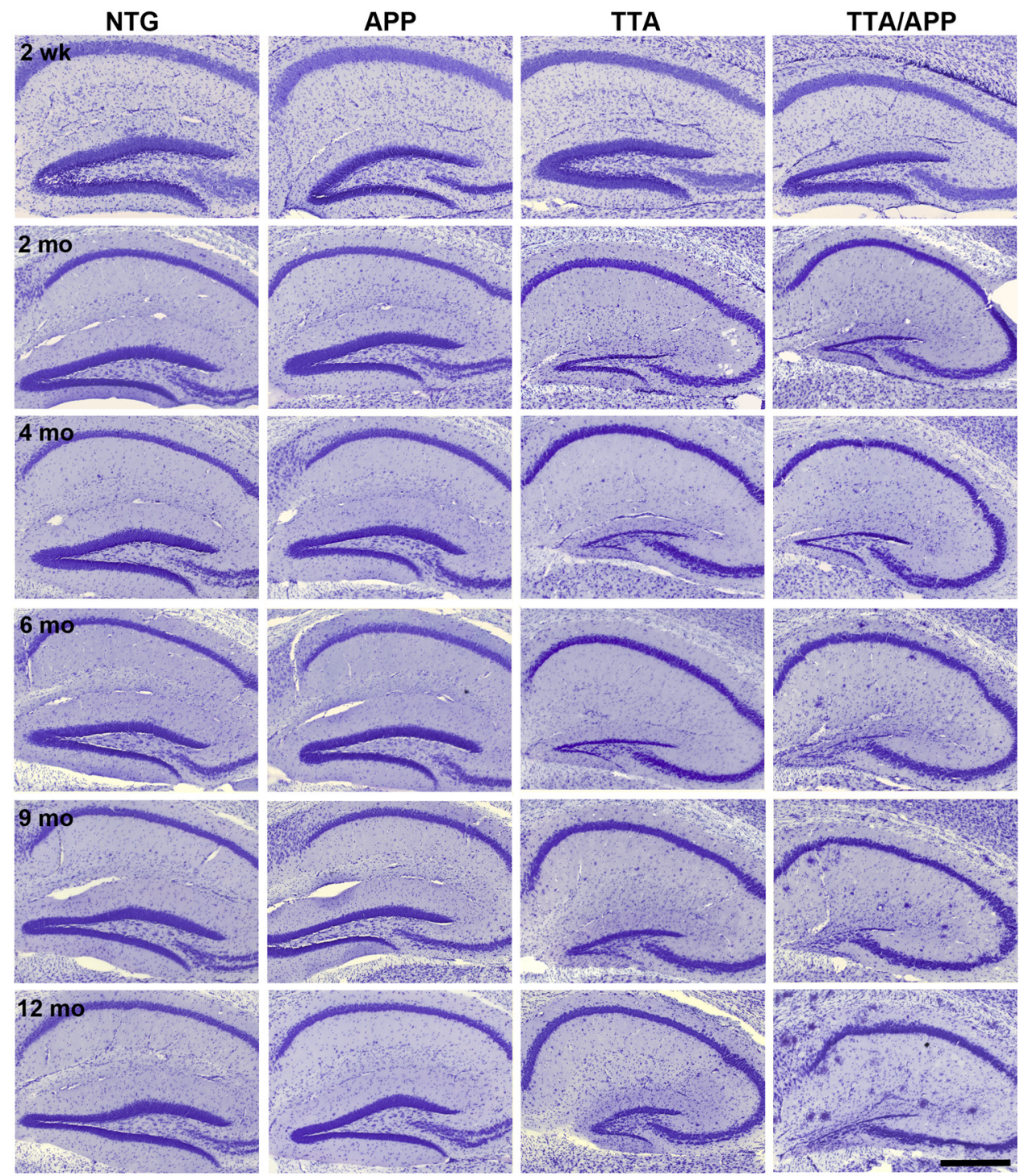

Figure 1. Hippocampal neurodegeneration is apparent in both the TTA/APP transgenic mouse model of Alzheimer's disease and in TTA single-transgenic controls. Cresyl violet-stained sections taken from mice ranging in age from 2 weeks to 12 months showed significant neuronal loss within the hippocampus of double-transgenic TTA/APP mice starting at 2 months of age. Singletransgenic TTA siblings on the same hybrid strain background also exhibited progressive neurodegeneration in the dentate gyrus. In both cases, the granule cell layer appears normal at 2 weeks of age. In contrast, single-transgenic APP mice showed no abnormalities and appeared similar to NTG at all time points examined. Scale bar, $400 \mu \mathrm{m}$.

of odds (LOD) scores calculated assuming a single locus of interest using Haley-Knott regression with 1000 permutations. A chromosomal region that likely contains our modifier was identified based on a $1.8-\mathrm{LOD}$ support interval, a method commonly used to approximate the $95 \%$ confidence interval with intercross data (Manichaikul et al., 2006).

\section{Statistical analysis}

Statistical analyses were conducted using GraphPad Prism 5.0. Two-way ANOVA followed by planned comparisons using Bonferroni post hoc test was used to analyze phenotypic differences between genotypes across multiple time points and background strains. Student's $t$ test with Welch's correction was used to analyze phenotypic differences between genotypes in the B6C3 F2 cross. A two-way repeated-measures ANOVA with Bonferroni post hoc test was used to analyze day-to-day and minuteby-minute data in the MWM and the contextual fear conditioning. Reported significance values reflect significance at Bonferroni corrected alpha levels. Correlation analyses between cell counts and dentate width were calculated by linear regression of the plotted data points. Unless otherwise stated, graphs display group mean \pm SEM.

\section{Results}

TTA expression causes atrophy of hippocampal granule cells Several years ago, we created a transgenic mouse model for Alzheimer's disease in which a double mutant form of the amyloid precursor protein (APPswe/ind) could be temporally controlled by the TTA (Jankowsky et al., 2005). Offspring carrying both CaMKII $\alpha$-TTA and tetO-APP transgenes produced high levels of $\mathrm{A} \beta$ peptide (derived from the proteolytic processing of APP) and developed age-related amyloid pathology (Jankowsky et al., 2005). In addition to the amyloid deposits, we also found that TTA/APP double-transgenic animals showed progressive neuronal atrophy that was most pronounced in the densely packed granule cell layer of the hippocampal dentate gyrus (Fig. 1).

To rule out the possibility that the hippocampal degeneration we saw in the TTA/APP mice was due to an integration site effect independent of APP overexpression, we examined the singletransgenic CaMKII $\alpha$-TTA and tetO-APP siblings. Unexpectedly, 
we found significant dentate granule cell loss in TTA single-transgenic mice (Fig. 1). Although neuronal loss was less severe in TTA mice than in the TTA/APP double-transgenic siblings, the size of the dentate gyrus was clearly reduced compared with NTG controls or tetO-APP single-transgenic mice, and with some variation in penetrance, became progressively more disorganized with time. In contrast, there were no gross anatomical differences in the CA1 pyramidal cell layer or in the neocortex.

Because our work generally focuses on age-related disease, our initial analysis only included adult mice starting at 2 months of age. Even at this relatively early time point, there was already a marked difference in the granule cell layer between TTA and NTG mice (Fig. 1). To distinguish whether TTA expression decreased neuronal number by limiting neurogenesis embryonically or by inducing degeneration postnatally, we harvested animals at 2 weeks of age, when the dentate gyrus has largely completed morphogenesis. We found no difference between genotypes in the structure of the granule cell layer at this age, suggesting that embryonic and early postnatal neurogenesis proceeded normally and that the observed cell loss either occurred between P14 and P30, when the tertiary germinal matrix migrates into the dentate gyrus (Altman and Bayer, 1990a,b), or subsequent to hippocampal development.

Because the CaMKII $\alpha$-TTA mouse line is widely used in neuroscience research, we investigated whether TTA singletransgenic siblings from other tet-off neurological disease models also displayed degeneration. We examined another tetracyclinecontrollable model for Alzheimer's disease (AD), the rTg4510 tet-off Tau mouse that also uses CaMKII $\alpha$-TTA to drive expression of microtubule-associated tau protein (Santacruz et al., 2005). As described in the original manuscript, bigenic rTg 4510 Tau mice exhibited massive atrophy of dentate granule cells and hippocampal pyramidal neurons over time (Fig. 2). However, consistent with our current findings, single-transgenic CaMKII $\alpha$-TTA siblings also had considerable dentate granule cell loss at all ages examined.

\section{Hippocampal granule cell loss is rescued by backcrossing the CaMKII $\alpha$-TTA line onto a C57BL/6 background}

Our results show that forebrain-specific TTA expression in the CaMKII $\alpha$-TTA line can cause severe degeneration of certain neuronal subtypes. However, this phenotype has never been reported in past studies with these mice. We contacted the original creator of this strain, Dr. Mark Mayford (Scripps Research Institute, La Jolla, CA), to enquire whether mice in his colony exhibited any sign of dentate degeneration. In response, Dr. Mayford kindly shared animals from his colony for us to examine. We first mated these animals with C57BL/6J (B6) mice to expand the cohort, and then killed both the breeders and their offspring to assess degeneration in the dentate gyrus. Neither the 7-month-old CaMKII $\alpha$-TTA animals imported from Dr. Mayford's colony nor their B6-derived offspring showed any sign of neurodegeneration (data not shown).
One difference between the TTA mice from the two AD models and TTA mice from the Mayford colony was that both AD models were maintained on hybrid strain backgrounds (B6/C3/ CBA for TTA/APP and B6/FVB/129 for TTA/Tau), while the Mayford colony had been made congenic on B6. The strain background we used to study the TTA/Tau model (B6/FVB/ 129) also differed from the genetic background on which it was originally reported [126S6SvEvTac/FVB F1 (Santacruz et al., 2005)]. Because previous studies suggest that genetic background plays a significant role in susceptibility to cytotoxicity (Spyropoulos et al., 2003; Eisener-Dorman et al., 2009; Morimoto and Kopan, 2009), we tested whether backcrossing our hybrid B6/C3/CBA CaMKII $\alpha$-TTA mice onto a pure C57BL/6 background would rescue neurodegeneration. Within five or six generations of backcrossing onto the B6 background (at which point the offspring are $>99 \%$ congenic), the overt dentate degeneration disappeared.

We performed a careful examination of granule cell layer morphology after continuing the B6 backcross for $>19$ generations. In the congenic line, the granule cell layer appeared completely normal at all time points examined (Fig. 3). To confirm this observation empirically, we measured the width of the granule cell layer from cresyl violet-stained sections for each animal. On the congenic C57BL/6J background, the width of the granule cell layer was nearly identical in the TTA single-transgenic animals and their age-matched NTG siblings at every time point examined (two-way ANOVA, $F_{(1,20)}=0.0602, p>0.05$ for genotype; $F_{(1,20)}=0.0115, p>0.05$ for time). In contrast, the width of the granule cell layer in our original hybrid B6/C3/CBA TTA mice was $42 \%$ thinner than in age-matched controls at 2-4 months (TTA, $32.1 \pm 4.3 \mu \mathrm{m}$ and NTG, $55.6 \pm 1.5 \mu \mathrm{m}$, Bonferroni post hoc test, $p<0.001)$ and almost $68 \%$ thinner by $6-9$ months (TTA, $18.5 \pm 2.9 \mu \mathrm{m}$ and NTG, $57.5 \pm 2.9 \mu \mathrm{m}, p<$ 0.001 ). These numbers also confirm the progressive nature of neurodegeneration in the hybrid TTA mice: the granule cell layer 
a
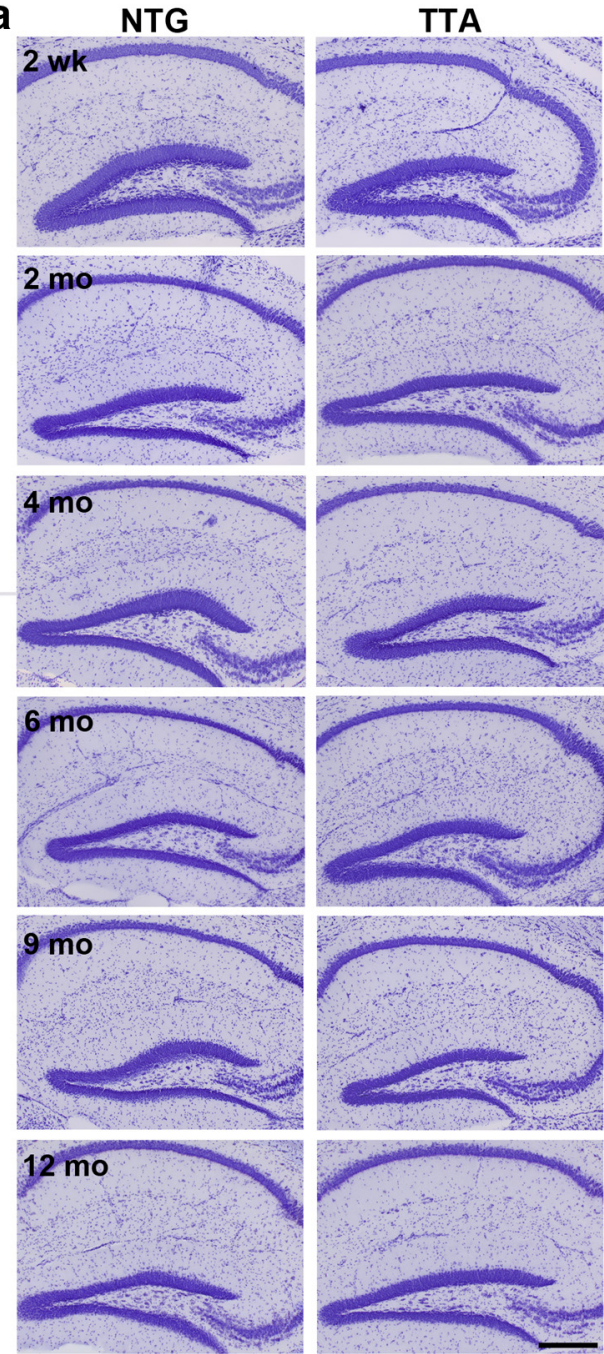

b $B 6 / C B A / C 3$ Hybrid
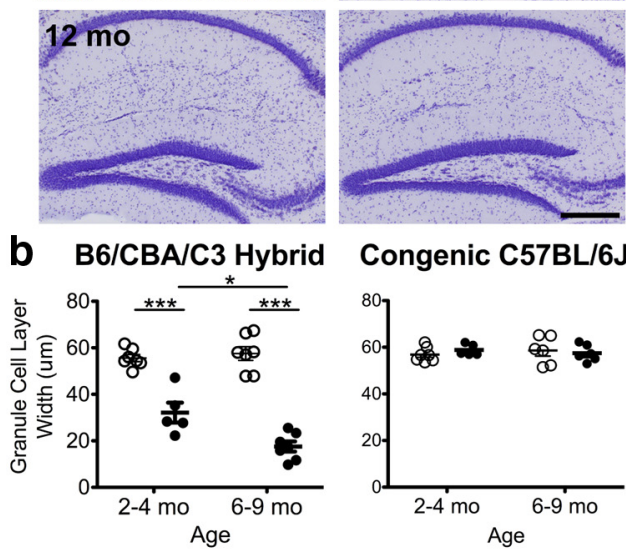

Congenic C57BL/6J

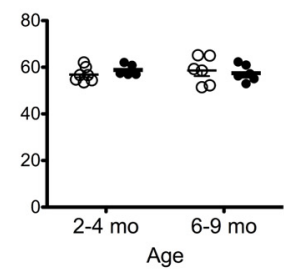

Figure 3. The $57 \mathrm{BL} / 6$ background protects against TTA-induced dentate granule cell loss. $\boldsymbol{a}$, The hippocampus of congenic B6 CaMKII $\alpha$-TTA mice appeared identical to NTG at all ages tested. $\boldsymbol{b}$, The width of the dentate granule cell layer was used to estimate the extent of degeneration in hybrid TTA transgenic mice and in mice backcrossed to $B 6$. On the $B 6 / C B A / C 3$ hybrid background, the width of the dentate granule cell layer was significantly thinner in TTAexpressing animals than in NTG siblings at both $2-4$ months and $6-9$ months of age. Moreover, the width decreased with age and was significantly thinner in TTA transgenic mice at 6-9 months than it was at 2 -4 months. In contrast, the width of the granule cell layer in congenic B6 TTA mice (backcross generation N19-N24) was no different from NTG at either age tested. $n=$ 5-7 mice per genotype for each age group. Open circle, NTG; filled circles, TTA. ${ }^{*} p<0.05$, ${ }^{* * *} p<0.001$, two-way ANOVA with Bonferroni post hoc test. Scale bar, $300 \mu \mathrm{m}$.

was significantly thinner at $6-9$ months than it had been at $2-4$ months $(p<0.05)$.

\section{Alleles in the $\mathrm{C} 3 \mathrm{H} / \mathrm{He}$ and $\mathrm{CBA}$ backgrounds increase susceptibility to TTA-induced neuronal loss}

Our discovery of dentate degeneration on the original hybrid background suggested that alleles from the $\mathrm{C} 3$ and $\mathrm{CBA}$ strains increase susceptibility to neuronal loss in TTA-expressing mice. However, because of the breeding strategy we used, the contribution of each genetic background in our hybrid $\mathrm{B} 6 / \mathrm{C} 3 / \mathrm{CBA}$ mice was unclear. To identify which of the two strains, C3 or CBA, most contributed to the observed neurodegeneration in the original hybrid line, we generated TTA transgenic mice containing varying amounts of each genetic background. We began by breeding our congenic $\mathrm{B} 6$ TTA mice to nontransgenic $\mathrm{C} 3 \mathrm{H} / \mathrm{HeJ}$ and $\mathrm{CBA} / \mathrm{J}$ animals to generate $\mathrm{B} 6 \mathrm{CBA}$ and $\mathrm{B} 6 \mathrm{C} 3 \mathrm{~F} 1 \mathrm{TTA}$ and NTG offspring, and then bred the B6C3 F1 TTA offspring back to NTG C3 and CBA. We also mated the B6C3 F1 TTA mice to NTG B6C3 F1 animals to generate $\mathrm{F} 2$ progeny. These crosses generated five genetically defined hybrid backgrounds for phenotypic analysis of TTA-associated dentate granule cell loss.

Both C3 and CBA strains promoted neuronal loss in TTA transgenic mice and there was a significant interaction between genotype and strain background (two-way ANOVA, $F_{(4,69)}=$ $12.87, p<0.001$ for strain; $F_{(4,69)}=137.1, p<0.001$ for genotype; $F_{(4,69)}=12.09, p<0.001$ for interaction; Fig. $\left.4 a-g\right)$. All hybrid backgrounds containing $50 \%$ or more of either C 3 or CBA showed significant granule neuron loss in 3-month-old TTA animals compared with NTG siblings. TTA expression reduced the width of the dentate granule cell layer by $14 \%$ on the B6C 3 F1 background (Bonferroni post hoc test, $p<0.05$ ) and by $30 \%$ on the B6CBA background $(p<0.001)$. We next investigated whether increasing the percentage of $\mathrm{C} 3$ or CBA could exacerbate the neurodegenerative phenotype. Mating B6C3 F1 TTA males with nontransgenic $\mathrm{C} 3$ females to theoretically raise the average C3 genetic contribution from $50 \%$ to $75 \%$ further exacerbated neuronal loss in TTA-expressing offspring. The width of the granule cell layer was $29 \%$ thinner in B6C3 $\times$ C3 TTA animals compared with their NTG cagemates $(p<0.001)$ and $15 \%$ thinner compared with the parental B6C3 F1 TTA mice $(p<0.05)$. The granule cell layer width was also significantly different between B6C3 F1 TTA mice and TTA-expressing B6C3 $\times$ CBA animals, showing a $15 \%$ width decrease in the $\mathrm{B} 6 \mathrm{C} 3 \times \mathrm{CBA}$ background $(p<0.05)$. To confirm that the reduction in granule cell layer width reflected cell loss and not simply a decrease in cell size, we counted the number of cells per linear micrometer along the main axis of each blade of the dentate. We chose the $\mathrm{B} 6 \mathrm{C} 3 \times$ C3 animals for analysis because these samples spanned the entire range of widths measured across all six backgrounds. We found a strong linear relationship between granule cell layer width and linear cell counts $\left(r^{2}=0.9461, p<0.001\right.$; Fig. $\left.4 h\right)$. The correlation was consistent across the full range of width measurements in both TTA and NTG mice, supporting our use of granule cell width as a proxy for neuronal number. Based on these measurements, our findings indicate that the C3 and CBA background strains are permissive for degeneration, and that either losing alleles from the $\mathrm{B} 6$ background or gaining them from the $\mathrm{C} 3$ and/or CBA backgrounds increases susceptibility to TTAinduced neuronal loss.

We next sought to identify potential loci that may modulate TTA-induced neuronal atrophy. We crossed $\mathrm{B} 6 \mathrm{C} 3 \mathrm{~F} 1 \mathrm{TTA}$ males to wild-type $\mathrm{B} 6 \mathrm{C} 3$ females to generate $\mathrm{B} 6 \mathrm{C} 3 \mathrm{~F} 2$ offspring that were examined for neuronal loss in the dentate gyrus. Of the 20 TTA transgenic animals examined, 15 showed thinning in the granule cell layer (Student's $t$ test with Welch's correction, $p<0.001$; Fig. $4 f-g$ ). In five of the $20 \mathrm{~B} 6 \mathrm{C} 3 \mathrm{~F} 2 \mathrm{TTA}$ transgenic mice, the granule cell layer appeared similar to the dentate gyrus in NTG animals. The two distinct phenotypes seen in the B6C3 F2 TTA cohort appeared to follow a 3:1 Mendelian ratio and suggest the presence of a single modifier of the neurodegenerative phenotype. 

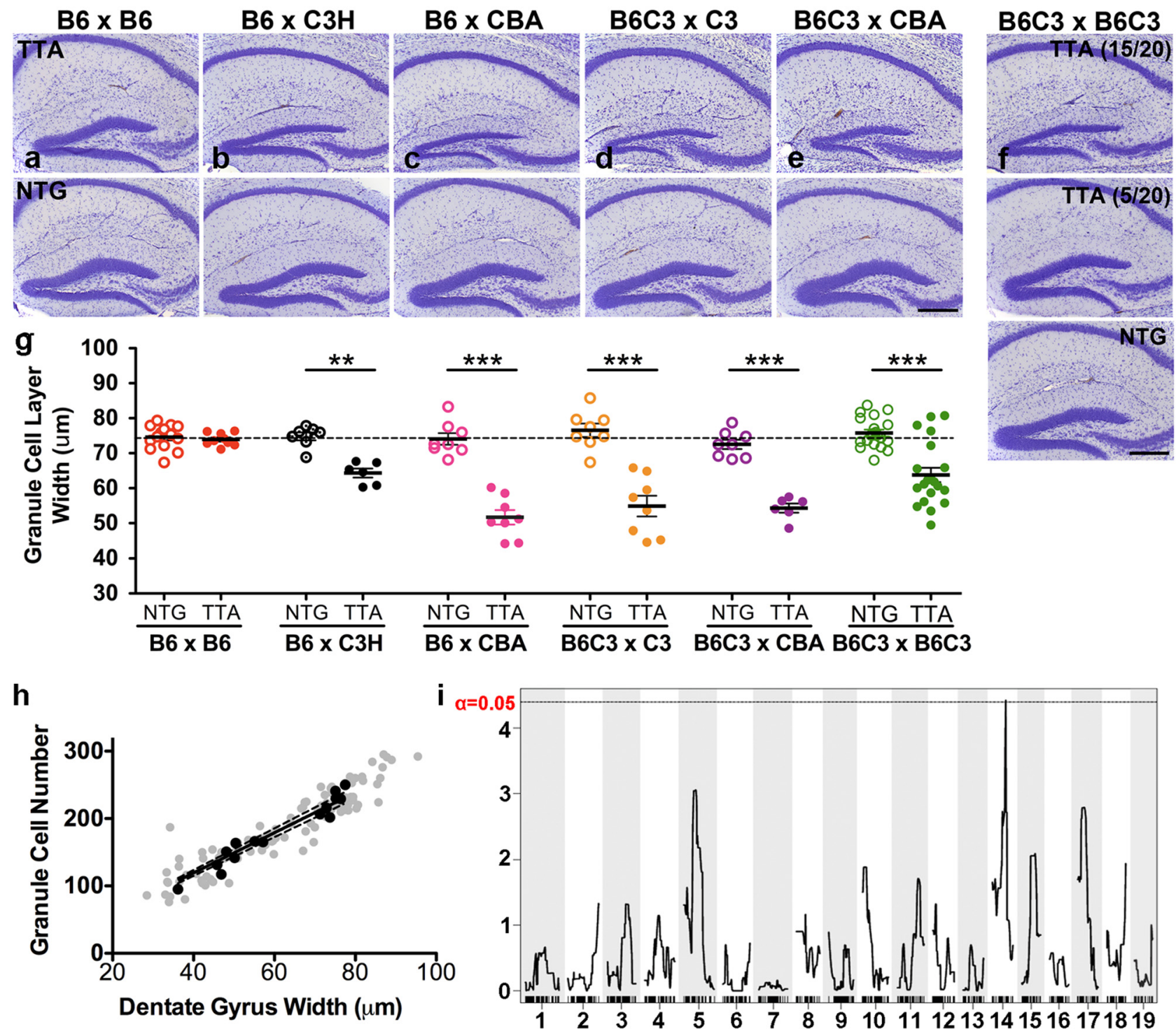

Figure 4. Both $\mathrm{C} 3 \mathrm{H} / \mathrm{He}$ and CBA contribute to dentate granule cell loss of the original hybrid background. $\boldsymbol{a}$, As expected from our initial analyses, the dentate granule cell layer was unaffected by TTA expression on the congenic B6 background. $\boldsymbol{b}$ - $\boldsymbol{e}$, However, on several F1 hybrid backgrounds derived from the B6 congenic line, TTA expression significantly decreased the width of the granule cell layer between 14\% (B6C3) and 30\% (B6CBA).f, Dentate degeneration was also present in TTA-expressing offspring from the B6C3 F1 intercross, where 15 of 20 F2 TTA mice exhibited thinning of the dentate granule cell layer compared with NTG siblings. One-quarter of the cohort (5 of 20) appeared indistinguishable from NTG. Representative images from both groups are shown. Scale bar, $300 \mu \mathrm{m} . \boldsymbol{g}$, The average width of the granule cell layer was measured for each background ( $n=6-20$ per genotype). One outlier, determined by Grubb's test, was removed from the B6C3 $\times$ CBA TTA group before analysis and appears near the mean for NTG animals of that background. Note that the $y$-axis starts at $30 \mu \mathrm{m}$. $\boldsymbol{h}$, Cell counts performed in C3B6 $\times$ C3 mice confirm that the width of the granule cell layer is linearly related to the number of granule cells remaining. Data points from each microscopic field are shown in gray (6-9 fields per mouse) and average values from each animal are shown in black ( $n=7-8$ per genotype). Solid line indicates the best-fit linear regression line for the average values, dashed lines indicate the $95 \%$ confidence interval. Note the $x$-axis starts at $20 \mu \mathrm{m}$. $\boldsymbol{i}$, Multipoint interval mapping was used to locate genetic modifiers of the neurodegenerative phenotype in the B6C3 F2 TTA cohort. LOD scores are plotted as a function of marker location in centimorgans, with the chromosome number designated. Black line represents the LOD significance threshold for $\alpha=0.05$, determined by Haley-Knott permutations. Odd-numbered chromosomes are shaded in light gray. ${ }^{*} p<0.05$, ${ }^{* * *} p<0.001$, two-way ANOVA with Bonferroni post hoc test.

To map the location of the modifier, we performed quantitative trait analysis on genomic DNA from the 20 TTA B6C 3 F2 animals using SNPs that differ between the B6 and the C3 backgrounds. Our analysis focused on finding markers homozygous for B6 in the five unaffected animals and heterozygous or homozygous for $\mathrm{C} 3$ in the 15 affected animals. R/qtl analysis identified one significant region on chromosome 14 with a LOD score of 4.42 (LOD threshold of $\alpha=0.05$ was 4.4; Fig. 4i). The locus with the next highest LOD score was on Chromosome 5, with a LOD score of 3.06. Visual analysis using 34 informative markers on Chromosome 14 suggested that the modifier lies between 39.37 and 43.77 cM (66.47-
78.06 Mbp region). Statistical analysis using R/qtl confirmed this location, identifying a 1.8-LOD-support interval of 39.698-43.698 cM (Moran et al., 2006). Our data does not rule out the possibility of multiple modifiers, but does reveal the locus on Chromosome 14 as a major determinant of TTAinduced neurodegeneration.

In search of a degeneration-resistant background for further study: unexpected strain-dependent behavioral consequences of TTA expression

Although B6 mice are resistant to TTA-associated neuronal loss, we found that aged animals from this strain perform poorly in 


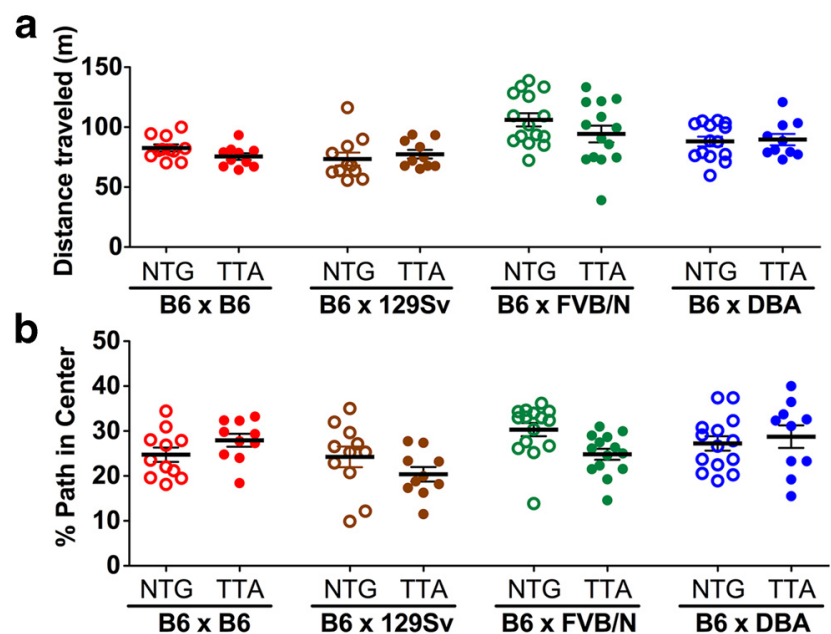

Figure 5. Strain background has a greater influence on open-field activity than does TTA expression. $\boldsymbol{a}$, Open-field analysis revealed significant differences between strains in the total distance traveled over the $30 \mathrm{~min}$ trial but no significant effect of TTA expression within any strain background ( $n=10-14$ per genotype per strain). $\boldsymbol{b}, 0 \mathrm{n}$ average, each group of mice spent between 20 and $30 \%$ of their distance traveled in the central third of the arena, with no significant difference between strains. Furthermore, in all strain backgrounds, expression of TTA had no effect on percentage path in center.

cognitive tests used to characterize mouse models of AD. We therefore sought a genetic background that exhibited better cognitive performance but maintained resistance to granule cell loss. F1 hybrids are commonly used in behavioral experiments and we examined three commonly used inbred strains (129X1/SvJ, DBA/ $1 \mathrm{~J}$, and $\mathrm{FVB} / \mathrm{NJ}$ ) based on their strong behavioral performance as B6 F1 hybrids and excellent breeding characteristics (Owen et al., 1997). We mated B6 congenic TTA males with wild-type B6, 129, DBA, and FVB females to generate congenic B6 and F1 hybrid offspring for comparison. We tested 2-month-old mice in three behavioral assays: the open field to assess exploratory activity and anxiety, Morris water maze to examine spatial learning and reference memory, and contextual fear conditioning for hippocampal-dependent one-trial associative learning.

Open-field assessment revealed significant differences in total distance traveled between different strain backgrounds (two-way ANOVA, $\left.F_{(3,87)}=10.24, p<0.001\right)$, but there was no significant effect of genotype on any background studied $\left(F_{(1,87)}=0.8632\right.$, $p=0.3554$ for genotype; Fig. $5 a$ ). Furthermore, there was no effect of genotype on the percentage of total distance spent in the center portion of the arena, which is often used as a rough measure of anxiety (two-way ANOVA, $F_{(1,87)}=0.8914, p=0.3477$ for genotype; Fig. 5b).

Based on past studies, we expected and found that all three F1 hybrids were considerably better at spatial learning and memory in the Morris water maze compared with congenic B6 mice. Although the F1 hybrids showed a more dramatic decrease in escape distance over the 5 training days compared with congenic B6 mice, the decrease in escape distance over the course of training was similar for both NTG and TTA on each background tested. This suggests that TTA expression does not alter the acquisition of this task for any of the F1 strains (Fig. $6 a-d$ ). Our testing protocol also allowed us to measure long-term memory for the location of the hidden platform using probe tests before training on days $2-6, \sim 24 \mathrm{~h}$ after the last trial of the previous day. Among the F1 animals, performance on daily probe trials was indistinguishable between genotypes suggesting that TTA expression did not alter consolidation or retrieval of spatial reference memory
Acquisition
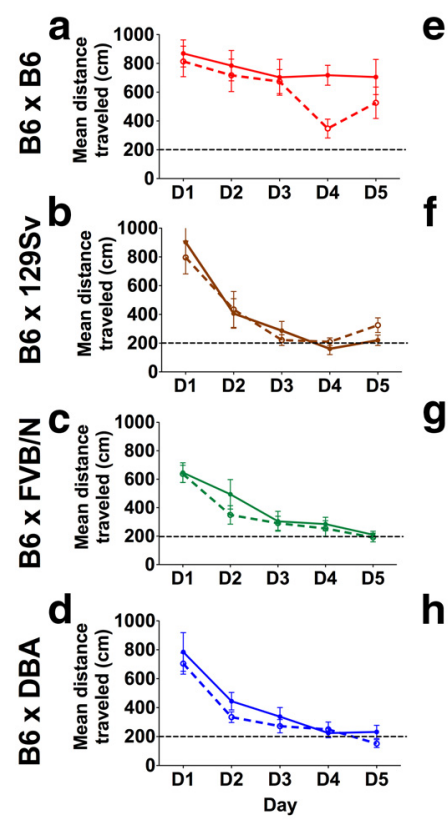

Figure 6. Both TTA expression and background strain influence performance in the Morris water maze. $\boldsymbol{a}-\boldsymbol{d}$, For all genotypes tested, escape distances decrease over time in the Morris water maze ( $n=10-14$ per genotype). Within each strain, acquisition by TTA mice was similar to NTG; however, as discussed in the Results, both genotypes performed poorly on the B6 background (NTG: dotted lines, open circles; TTA: solid lines, filled circles). Dotted lines mark 200 $\mathrm{cm}$ mean distance traveled. $\boldsymbol{e}-\boldsymbol{h}$, Long-term probe trials, conducted $24 \mathrm{~h}$ after each training session, measured the consolidation of spatial memory for the trained platform location. In general, the percentage of total swim path spent in the target quadrant increases with continued training. However, this trend was not apparent for TTA mice on the B6 background, where TTA mice swam less distance in the target quadrant than their NTG siblings on probe trials 4 and 5. Dotted lines mark chance performance of $25 \%$. Open bars, NTG; filled bars, TTA. Two-way RM ANOVA with Bonferroni post hoc test, ${ }^{*} p<0.05,{ }^{* *} p<0.01$.

(Fig. $6 e-h$ ). Strain background rather than genotype appeared to have the greatest effect on water maze performance across probe trials [two-way repeated-measures (RM) ANOVA, $F_{(3,47)}=$ $6.432, p=0.001$ ], and post hoc comparisons of performance on probe trial 5 revealed that NTG B6 animals spent significantly less time in the target quadrant compared with NTG mice on F1 backgrounds (Bonferroni post hoc test, $p<0.01$ for B6 congenic vs B6129, B6DBA, and B6FVB).

Of the four strain backgrounds, congenic B6 mice showed the worst acquisition and long-term recall of the platform location. Within the congenic B6 group, expression of TTA appeared to impair acquisition and subsequently prevent recall of the trained position. Congenic B6 TTA mice showed no improvement over the course of training (one-way RM ANOVA, $F_{(4,9)}=0.8196, p>$ $0.05)$, while NTG displayed a small but significant reduction in distance traveled across days (one-way RM ANOVA, $F_{(4,10)}=$ 3.705, $p<0.05)$. However, there was no statistical difference between genotypes when compared directly, likely reflecting the relatively small improvement observed in the NTG mice (twoway RM ANOVA, $\left.F_{(1,19)}=2.47, p>0.05\right)$. Although acquisition trials suggest the B6 TTA mice did not learn the task, probe tests for immediate recall conducted at the end of training each day revealed that performance of both genotypes improved over time, concentrating a greater fraction of their swim path in the correct quadrant with more days of training (two-way RM ANOVA, $F_{(4,76)}=4.39, p<0.01$; data not shown). Performance of the TTA mice was no different from NTG during these immediate 


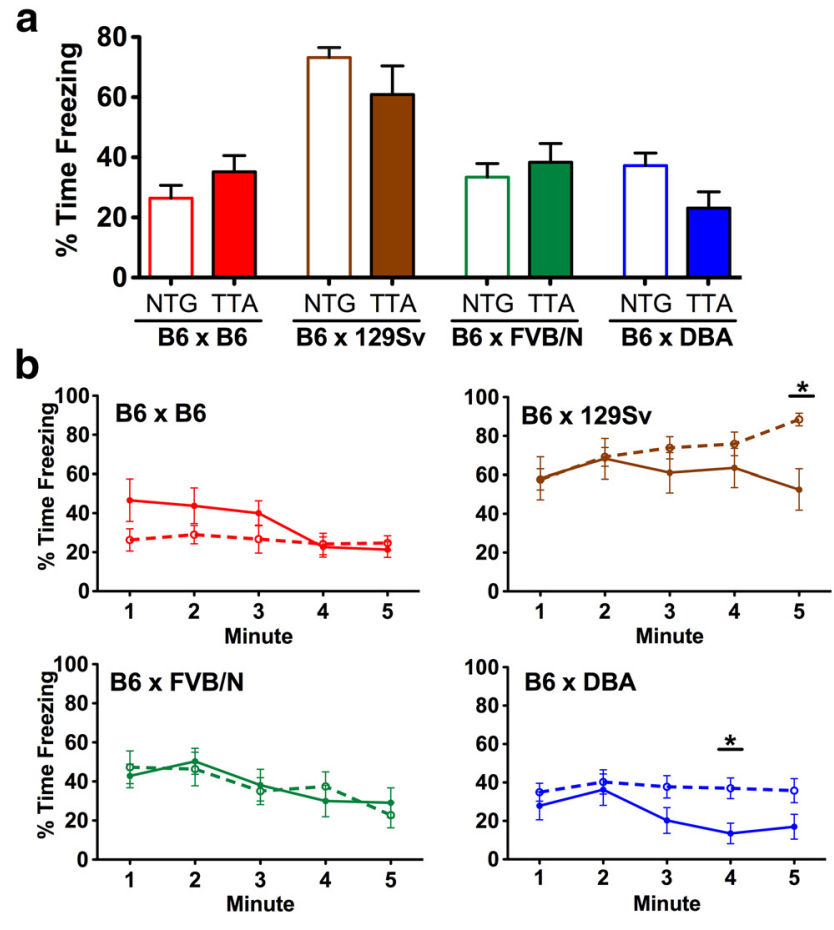

Figure 7. Strain-dependent effects of TTA expression on contextual fear conditioning. $\boldsymbol{a}$ Freezing responses during the 5 min context test varied significantly with strain, but the average percentage time spent freezing did not differ between genotypes on any background tested. $\boldsymbol{b}$, Minute-by-minute freezing for the four strain backgrounds (NTG: dotted lines, open circles; TTA: solid lines, filled circles). On the B6129 background, there was a noticeable divergence between the two genotypes over time. Similarly, freezing responses in B6DBA TTA and NTG mice diverged significantly over time during testing. In contrast, there was no difference in freezing between genotypes on the B6FVB or congenic (57BL/6 background over time ( $n=$ 10 -14 per genotype). Two-way RM ANOVA with Bonferroni post hoc test, ${ }^{*} p<0.05$.

probe tests (two-way RM ANOVA, $F_{(1,76)}=0.1876, p>0.05$ ). In contrast, long-term recall tested $24 \mathrm{~h}$ after training suggested that TTA impairs consolidation of this memory (two-way RM ANOVA, $F_{(1,21)}=8.85, p<0.01$ for genotype; Fig. 6e). Congenic B6 TTA mice traveled significantly less distance in the target quadrant than NTG during the $24 \mathrm{~h}$ probe trials (Bonferroni post hoc test, probe $4, p<$ 0.01 ; probe $5, p<0.05$ ). Thus, not only do B6 mice perform poorly in the Morris water maze compared with F1 hybrids, the expression of TTA in the B6 background may further impair their ability to learn this task.

Animals were also tested in contextual fear conditioning, which uses the innate freezing response as a measure of associative memory between the conditioning chamber and an aversive unsignaled foot shock. Freezing levels measured $24 \mathrm{~h}$ after training differed dramatically between strains, with B6129 freezing for significantly more time than any other background (one-way ANOVA, $F_{(3,49)}=24.17$, Bonferroni post hoc test, $p<0.001$ for B6129 vs B6 congenic, B6DBA, and B6FVB; Fig. 7). While we found no effect of TTA expression on the average percentage of time freezing (Fig. 7a), analyses of minute-by-minute responses revealed a more complex picture for the B6DBA and B6129 strains (Fig. $7 b$ ). When examined as a function of time, contextual freezing in B6DBA mice showed significant effects for both genotype and time (two-way RM ANOVA, $F_{(4,88)}=2.55, p<$ 0.05 for time; $F_{(1,88)}=4.41, p<0.05$ for genotype; $F_{(4,88)}=1.63$, $p=0.17$ for interaction). Post hoc analysis revealed a significant difference in freezing levels between TTA and NTG during minute 4 of the 5 min test (Bonferroni post hoc test, $p<0.05$ ). Similarly, minute-by-minute analysis of freezing in B6129 mice revealed a marked divergence between genotypes over time. Although there was no main effect of genotype on the B6129 background (two-way RM ANOVA $F_{(1,84)}=1.59, p=0.22$; Fig. 7), there was a significant interaction between genotype and time $\left(F_{(4,84)}=5.016, p<0.01\right)$, and post hoc analysis revealed a significant difference in freezing levels between TTA and NTG during the final minutes of the test (Bonferroni post hoc test, $p<0.05$ ). To confirm these results, we repeated the test in a separate set of naive TTA and NTG B6129 F1 animals that had not undergone any previous behavioral testing. We again saw a similar pattern of freezing over time on the B6129 background, where NTG mice trended upward, while TTA mice trended down (data not shown), yielding significant effects for genotype, time, and interaction (two-way RM ANOVA, $F_{(1,13)}=5.191, p<0.05$ for genotype; $F_{(4,52)}=3.372, p<0.05$ for time; and $F_{(4,52)}=6.013, p<0.001$ for interaction). As with the original cohort, post hoc analysis revealed a significant difference in freezing between TTA and NTG during the final minutes of the test (Bonferroni post hoc test, $p<0.001$ ). In contrast to the B6129 and B6DBA animals, TTA expression caused no significant changes in average freezing or minute-by-minute responses on B6FVB or congenic B6 backgrounds (Fig. 7b). In summary, our behavioral data across the three assays indicate that forebrain-specific neuronal TTA expression can have varying behavioral effects depending on the strain background and the behavioral task under study.

Because our initial studies demonstrated that genetic background contributes to TTA-associated neuronal loss, we tested for neuronal loss in the F1 hybrid mice used for behavioral testing. Congenic B6 mice again showed no observable degeneration and TTA expression on this background caused no change in the width of the dentate granule cell layer (Fig. 8a). However, consistent with our previous results examining the $\mathrm{C} 3$ and CBA hybrid backgrounds, we found a significant effect of genotype, strain, and their interaction on dentate granule cell layer width across the four strains examined (two-way ANOVA, $F_{(3,56)}=22.97, p<$ 0.001 for strain; $F_{(1,56)}=140.0, p<0.001$ for genotype; $F_{(3,56)}=$ 20.33, $p<0.001$ for interaction). Although not as severe as in B6CBA F1 mice, TTA expression caused some thinning of the granule cell layer on all of the behaviorally tested $\mathrm{F} 1$ strains (17\% for B6DBA, 21\% for B6FVB, and 27\% for B6129; Bonferroni post hoc test, all $p<0.001$; Fig. $8 b-e)$. Because these strains are so genetically diverse, their common phenotype suggests that the loss of B6 homozygosity rather than introduction of a shared allele is likely responsible.

\section{Early doxycycline treatment protects against TTA-associated} neuronal loss in the adult

One final question that arose during the review of this study was whether dox treatment could alter the progression or severity of TTA-associated phenotypes; specifically, whether it could limit the overt neuronal loss we observed. We returned to archival tissue generated during the initial characterization of the tetOAPPswe/ind transgenic lines for an answer to this question. When the tetO-APPswe/ind mice were first created, we performed control experiments to test whether dox suppression was complete enough to prevent amyloid formation even in very old animals. These mice were intended as sentinels for transgene leak, on the premise that a small amount of residual expression would appear as late-onset amyloid formation. In these experiments, we treated bigenic CaMKII-TTA/tetO-APPswe/ind mice and their single-transgenic and NTG cagemates with dox throughout life until 17-24 months of age. These mice were on the same mixed hybrid background (B6/C3/CBA) as mice shown in Figure 1, but 


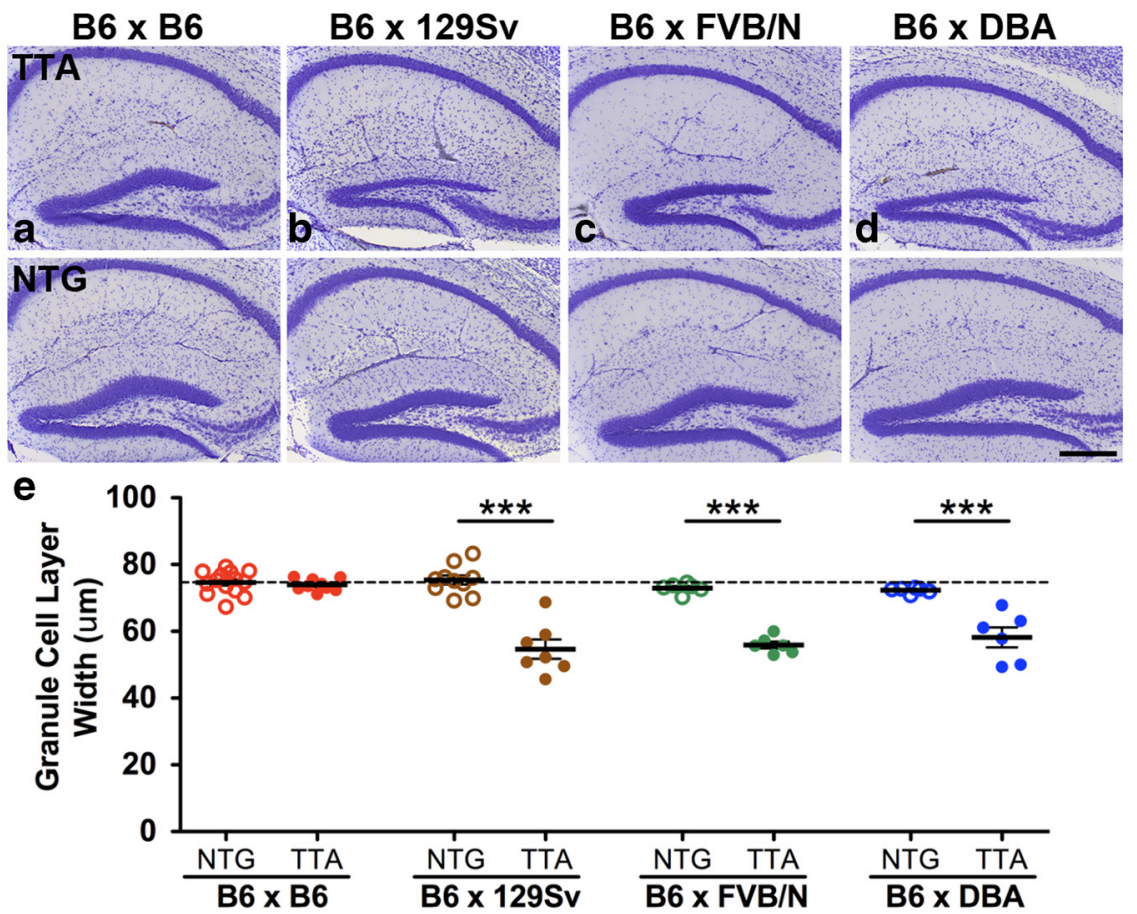

Figure 8. TTA expression decreases granule cell layer width on F1 backgrounds. $\boldsymbol{a}$, Consistent with our previous results, the structure of the dentate gyrus was indistinguishable between TTA and NTG on the congenic C57BL/6 background. $\boldsymbol{b}-\boldsymbol{d}$, By comparison, TTA expression caused some thinning of the granule cell layer on the B6129, B6FVB, and B6DBA F1 backgrounds. Scale bar, $300 \mu \mathrm{m} . \boldsymbol{e}, \mathrm{B} 6129, \mathrm{~B} 6 \mathrm{FVB}$, and B6DBA TTA-expressing animals have significantly thinner dentate granule cell layers compared with NTG siblings ( $n=6-14$ per genotype). Two-way ANOVA with Bonferroni post hoc test, ${ }^{* * *} p<0.001$.

were derived from mating CaMKII-TTA with tetO-APPswe/ind Lines 107 or 885 , carrying the same APP transgene as Line 102 (shown in Fig. 1). Both TTA single-transgenic and bigenic APP/TTA offspring from Line 885 (Fig. 9a-c) and Line 107 (data not shown) exhibited obvious neuronal loss in the dentate gyrus identical to that of Line 102. However, mice reared on dox were protected from granule cell degeneration. The granule cell structure of TTA and APP/ TTA animals reared on dox was indistinguishable from singletransgenic tetO-APP (Fig. $9 d-f$ ) and NTG (data not shown) even at very late ages long after degeneration would have appeared in untreated animals. This finding suggested that the conformation of TTA and/or its ability to bind DNA were key determinants of its ability to promote granule cell loss.

Having shown that lifelong dox treatment can prevent cell loss in the dentate of TTA transgenic mice on a particularly susceptible hybrid strain background (B6/C3/CBA), and that the phenotypic changes in untreated mice begin between 2 and 8 weeks of age, we wondered whether dox treatment during this period of postnatal development might alter the course of TTA toxicity in the adult. Ongoing work in our group has shown that suppression of transgenic APP during this critical window has lifelong behavioral ramifications (Rodgers et al., 2012), and dox treatment between the first postnatal days and sexual maturity 6 weeks later has become the standard procedure for rearing bigenic animals in our colony. We therefore examined the dentate gyrus of NTG and TTA B6FVB F1 mice that had been reared on dox from P1-P3 until P41-P43. The mice were harvested at 7.5 months of age, following 6 months of exposure to active TTA, which would have caused $20 \%$ granule cell loss in untreated mice (Fig. 8). Surprisingly, dox treatment during the first 6 weeks of life provided long-term protection against TTAassociated neurotoxicity (Fig. 10). Width measurements from cresyl violet-stained sections confirmed the preservation of the granule cell layer by early dox treatment (NTG vs TTA, $p=0.62$, Student's $t$ test; Fig. 10c). This finding raises the possibility that TTA most strongly impacts granule neurons during postnatal development, and that inactivating its transcriptional capacity during this critical window may protect them against TTA-mediated toxicity later in life.

\section{Discussion}

The underlying assumption of the tet-off system is that the transactivator protein does not influence the physiology or behavior of the model, and that all observed phenotypes can be attributed to the transgene under study. Here we show this assumption is incorrect: single-transgenic TTA mice are not always identical to their nontransgenic siblings. We found that TTA expression can cause strain-dependent neuronal loss in the dentate granule cell layer and behavioral alterations in two common assays of cognitive performance. Because the tet-off and tet-on systems are so widely used in neuroscience research, identifying potential issues caused by TTA expression is important to ensure correct attribution of phenotypes caused by the transgene controlled by TTA and those due to TTA itself.

Our study focused on cell loss in the dentate gyrus because of its overt phenotype-in most cases, we could genotype animals based solely on appearance of the granule cell layer. The width measurements we used to assess degeneration allowed us to quickly estimate cell loss in nearly 200 animals across 10 different strain backgrounds. Structural differences caused by TTA expression were not obvious in other areas we examined, but careful nonbiased stereology has revealed significant decreases in cell count within the CAl region of CaMKII $\alpha$-TTA transgenic mice at later ages (E. Schaeffer, M. West, and J. Jankowsky, unpublished data). Neuronal loss in the dentate may have been more prominent because of the tightly packed arrangement of cells in this region, making their degeneration easier to spot, or because dentate granule cells may be particularly susceptible to TTA-induced toxicity, making them more likely to die. We found that the dentate gyrus of 2-weekold TTA animals appeared normal, suggesting embryonic hippocampal development is not affected by TTA. Dox treatment between P1-P42 appeared to protect against TTA-induced granule cell loss, raising the possibility that the granule cell layer is most sensitive to TTA-mediated toxicity during postnatal development. An alternative explanation for diminished size of the granule cell layer in TTA mice may be loss of adult neurogenesis. However, previous studies in adult rodents suggest that adult neurogenesis adds new cells rather than replace existing ones (Bayer et al., 1982; Crespo et al., 1986; Kempermann et al., 2003), increasing the density of neurons in the granule cell layer without altering its volume (Imayoshi et al., 2008). The decrease in granule cell layer width observed in the original hybrid TTA mice is more consistent with TTA either causing cell death in postmitotic granule cells or impacting postnatal development than with loss of adult neurogenesis.

While the mechanism of TTA-associated toxicity in dentate granule cells remains unclear, the phenomenon is neither unique 


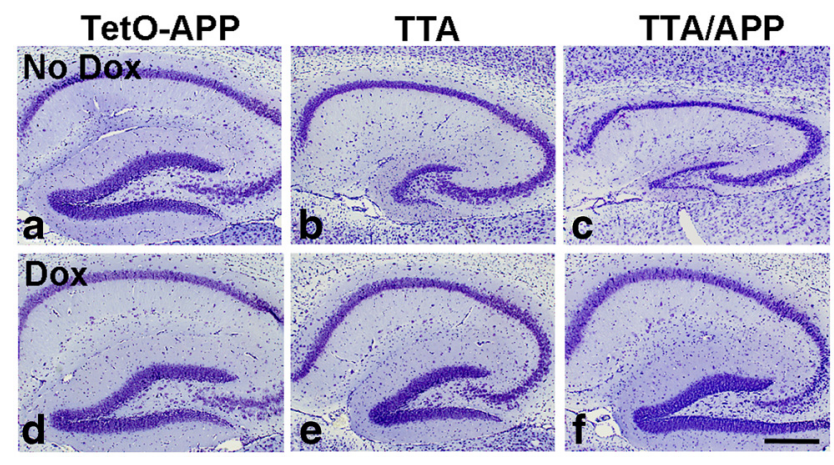

Figure 9. Lifelong doxycycline treatment prevents degeneration of the dentate granule cell layer. Animals maintained on dox throughout life show no evidence of granule neuron loss, even in the most severely affected strain background and at ages well beyond when half these cells would be gone from untreated animals. $\boldsymbol{a}-\boldsymbol{c}$, In the original B6/C3/CBA hybrid background, both TTA and TTA/APP mice at $6-9$ months of age exhibited substantial granule cell loss compared with tet 0 -APP and NTG (data not shown). $\boldsymbol{d}$-f, Following lifelong dox treatment, the granule cell layer of 24-month-old TTA and TTA/APP mice appears identical to tet0-APP (and NTG, data not shown). Animals shown here were derived from intercrosses of CaMKIITTA $\times$ tet0-APPswe/ind Line 885 . Similar results were observed with tet0-APPswe/ind Line 107 (data not shown) ( $n=4-6$ per genotype). Scale bar, $300 \mu \mathrm{m}$.
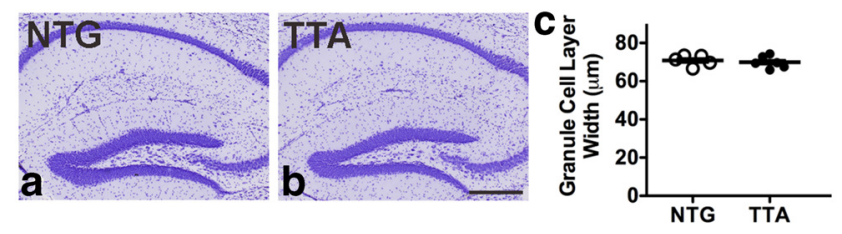

Figure 10. Postnatal doxycycline treatment provides long-term protection against granule cell loss. Dox treatment from shortly after birth until 6 weeks of age protects the integrity of the dentate gyrus for many months after the drug is removed. $\boldsymbol{a}, \boldsymbol{b}$, TTA transgenic mice generated on a B6FVB F1 background would normally show $20 \%$ reduction in granule cell layer width by 3 months of age. In contrast, early dox treatment (P1-P3 until P41-P43) protects against overt neuronal loss in the dentate gyrus of TTA mice on this background up to 6 months later. Images show cresyl violet staining from FVBB6 F1 mice at 7.5 months of age following dox rearing until 6 weeks of age. Scale bar, $300 \mu \mathrm{m}$. c, Measurements of granule cell layer width confirm that neuronal loss is ameliorated by inactivating TTA during postnatal development ( $n=5-6$ per genotype, $p=0.62$, Student's $t$ test).

to this cell population nor to this protein. Severe cerebellar atrophy was reported in transgenic rats expressing TTA under control of the GFAP promoter (Barton et al., 2002). Outside of the CNS, TTA and reverse tetracycline-controlled transactivator (rTTA) expression has been linked to emphysema-like symptoms in the lung, cardiomyopathy in the heart, and microphthalmia with lens opacity in the eye (McCloskey et al., 2005; Sisson et al., 2006; Morimoto and Kopan, 2009; P. Overbeek, unpublished observation). TTA can alter gene expression even in the absence of a responsive transgene (McCloskey et al., 2005), possibly through the VP16 subunit, which can interact with endogenous transcription factors (Sadowski et al., 1988; Goodrich et al., 1993; Wilson et al., 1997). Similar consequences have been reported with other transcriptional activators. Expression of Crerecombinase and its controllable variant $\mathrm{CreER}^{\mathrm{T} 2}$ causes cytotoxicity in a variety tissues in vivo, including brain, heart, pancreas, thymus, and reproductive organs, with the nature and severity of the phenotype depending on the age and cell type in which the proteins are expressed (Schmidt et al., 2000; Buerger et al., 2006; Forni et al., 2006; Lee et al., 2006; Naiche and Papaioannou, 2007; Higashi et al., 2009). The TTA/tetO and Cre/loxP systems are attractive for their spatial and temporal control of transgene expression; however, both come with the risk of significantly altering cellular physiology.
Consistent with the hypothesis that TTA toxicity is caused by off-target interactions involving other proteins or promoters, we found that lifelong doxycycline treatment prevented neuronal loss in the dentate gyrus. Barton and coworkers (2002) observed similar rescue of cerebellar degeneration by lifelong doxycycline treatment in GFAP-TTA transgenic rats. Under these conditions, expression of TTA is expected to persist but to adopt a different three-dimensional conformation when bound to doxycycline (Gossen and Bujard, 1992). This structural switch was designed to control TTA's association with the tetO promoter, but may also affect its interaction with other cellular factors. Transcriptionally active TTA appears to be most problematic during neural development, as both Barton et al. (2002) and we found acute postnatal doxycycline treatment sufficient to provide longlasting protection against neuronal loss. Doxycycline-mediated protection is not shared by all tissues, and studies documenting physiological effects of TTA and rTTA in heart and lung have observed little improvement following lifelong treatment (McCloskey et al., 2005; Morimoto and Kopan, 2009). Within the brain, however, delaying transcriptional activity with doxycycline may offer a simple means of limiting TTA-associated neurotoxicity during development.

Like many models of cellular toxicity, we found that genetic background was a significant determinant of TTA-induced neurodegeneration. Transgenic TTA expression caused thinning of the dentate granule cell layer in a variety of mixed background strains, but not in congenic B6 mice. Morimoto and Kopan (2009) described a similar strain disparity in mice expressing lung-specific rtTA. On an outbred CD1 background, doxycyclinereared rtTA transgenic mice showed impaired alveologenesis, decreased expression of surfactant-associated proteins, and premature death, while animals expressing the same transgene on a B6 background were largely unaffected. Genetic background could influence cell loss by multiple mechanisms, including strain-specific alleles that (1) confer susceptibility to or protect against TTA toxicity, (2) alter the level of TTA expression, or (3) affect TTA activity and DNA binding. Although we and others have been unsuccessful using commercially available antibodies raised against TTA (Krestel et al., 2001; Zhou et al., 2009), past work using a tet-responsive lacZ reporter line has shown that a single generation backcross of hybrid TTA mice dramatically altered the proportion of reporterexpressing cells in the offspring, consistent with a straindependent effect on the level of TTA expression or its activity (Robertson et al., 2002). Our own data support the hypothesis that $\mathrm{B} 6$ carries a recessive allele offering protection against TTAmediated physiological insult, as the congenic resistance to dentate degeneration was lost in all five F1 backgrounds we studied. Consistent with this prediction, our SNP mapping of TTA transgenic mice on a B6C3 F2 background uncovered a $12 \mathrm{Mbp}$ region on Chromosome 14, in which homozygosity for B6 was associated with preserved dentate structure. This region contains 102 coded genes (www.ensembl.org), one of which, Clusterin (also known as ApolipoproteinJ), was recently identified as a risk factor for late-onset Alzheimer's disease (Harold et al., 2009; Seshadri et al., 2010). Past work supports an interaction between TTA and Clusterin, with Clusterin expression elevated twofold in TTA transgenic myocytes (McCloskey et al., 2005). Clusterin is expressed throughout the body and can have both antiapoptotic and proapoptotic roles depending on which splice form is expressed (de Silva et al., 1990). While there are no coding differences between the background strains we examined, the divergent effects of different splice variants raises the potential for intronic or extragenic alleles to play a major role in determining the net outcome of expression from 
this locus. Notably, of the five strains we examined, the two most closely related strains, $\mathrm{C} 3 \mathrm{HeJ}$ and $\mathrm{CBA}$, displayed the most pronounced degeneration (Beck et al., 2000).

Strain background also influenced behavioral performance in TTA transgenic mice. No single task or any single background was consistently affected by TTA expression. When expressed on a congenic B 6 background, TTA impaired spatial reference memory (as assessed by the Morris water maze), while associative memory (assessed by contextual fear conditioning) was unaffected. Conversely, TTA expression on two of the F1 strains caused associative memory to decay more quickly than NTG, but had no effect on spatial memory in the water maze. The impact of TTA on hippocampal-dependent behavior in B6 animals was surprising given their resistance to TTA-induced granule cell loss. However, the CaMKII $\alpha$ promoter expresses throughout the forebrain, where other brain regions implicated in spatial learning and memory may be affected by TTA. Using congenic and F1 strain backgrounds distinct from those tested here (C57B/6NTac and F1 C57BL6N/129S6SvEvTac), McKinney et al. (2008) have also described strain-dependent behavioral differences in CaMKII $\alpha$-TTA transgenic mice. On these backgrounds, TTA expression diminished locomotor activity in the open field, lightdark box, rotorod, and elevated plus maze, but did not affect cognitive performance in Morris water maze or cued fear conditioning. Our findings demonstrate that the same transgene can have substantially different behavioral effects depending on the strain background in which it is expressed.

Two questions our data did not address are whether TTA contributes to disease progression in tetracycline-regulated models of neurodegeneration and, subsequently, whether doxycycline treatment abates cell loss and functional decline through its effect on TTA rather than through the disease transgene it controls. We found that lifelong dox treatment prevents cell loss in both TTA and TTA/APP animals, raising the possibility that a conformational change in TTA may contribute to phenotypic arrest and recovery after dox treatment. Our study does demonstrate that the influence of TTA is highly dependent on the outcome measure used in each experimental situation (i.e., cognitive behavior, motor performance, neuronal loss, aggregated protein levels, etc.) and the strain background on which it is studied. Our results with a particular genetic background or outcome measure do not necessarily extrapolate to other experimental situations, and a reversal of TTA-induced damage in the dentate might incorrectly cast doubt on past studies showing structural or functional recovery after doxycycline treatment (Tremblay et al., 1998; Yamamoto et al., 2000; Fischer et al., 2005; Santacruz et al., 2005; Muyllaert et al., 2008; Wang et al., 2008; Lin et al., 2009; Cheng et al., 2011). Rather than attempting to reproduce the exact outcome measures and strain backgrounds used in past experiments, it may be more constructive to include this critical control in future studies.

In summary, the TTA protein should be recognized for what it is - an artificial protein not normally found in mammalian cells. There is likely no strain background that is completely immune from the physiological or functional impact of TTA expression. Rather, each strain offers a unique genetic landscape that governs how different cells respond to the presence of TTA. These differences mean that the background strain can be tailored to each experimental situation so that the impact of TTA expression is minimized. However, this approach is too costly and time-consuming for most studies. A more realistic set of recommendations for future work using the tet-off system is to maintain transgenic lines on a clearly defined strain background that can be easily reproduced, and to always examine TTA single-transgenic controls alongside bigenic and non- transgenic siblings. Where experimentally appropriate, doxycycline treatment during periods of greatest susceptibility in development may preserve neural structure for study in the adult. The tettransactivators offer unparalleled control over the onset and duration of transgene expression, but require thorough evaluation to ensure that the observed phenotypes can be accurately attributed to the real transgene under study.

\section{References}

Altman J, Bayer SA (1990a) Mosaic organization of the hippocampal neuroepithelium and the multiple germinal sources of dentate granule cells. J Comp Neurol 301:325-342.

Altman J, Bayer SA (1990b) Migration and distribution of two populations of hippocampal granule cell precursors during the perinatal and postnatal periods. J Comp Neurol 301:365-381.

Alvarez-Saavedra M, Sáez MA, Kang D, Zoghbi HY, Young JI (2007) Cellspecific expression of wild-type MeCP2 in mouse models of Rett syndrome yields insight about pathogenesis. Hum Mol Genet 16:2315-2325.

Barton MD, Dunlop JW, Psaltis G, Kulik J, DeGennaro L, Kwak SP (2002) Modified GFAP promoter auto-regulates tet-activator expression for increased transactivation and reduced tTA-associated toxicity. Brain Res Mol Brain Res 101:71-81.

Bayer SA, Yackel JW, Puri PS (1982) Neurons in the rat dentate gyrus granular layer substantially increase during juvenile and adult life. Science 216:890-892.

Beck JA, Lloyd S, Hafezparast M, Lennon-Pierce M, Eppig JT, Festing MF, Fisher EM (2000) Genealogies of mouse inbred strains. Nat Genet 24:23-25.

Buerger A, Rozhitskaya O, Sherwood MC, Dorfman AL, Bisping E, Abel ED, Pu WT, Izumo S, Jay PY (2006) Dilated cardiomyopathy resulting from high-level myocardial expression of Cre-recombinase. J Card Fail 12:392-398.

Calhoun ME, Wiederhold KH, Abramowski D, Phinney AL, Probst A, Sturchler-Pierrat C, Staufenbiel M, Sommer B, Jucker M (1998) Neuron loss in APP transgenic mice. Nature 395:755-756.

Cheng N, Cai H, Belluscio L (2011) In vivo olfactory model of APP-induced neurodegeneration reveals a reversible cell-autonomous function. J Neurosci 31:13699-13704.

Crespo D, Stanfield BB, Cowan WM (1986) Evidence that late-generated granule cells do not simply replace earlier formed neurons in the rat dentate gyrus. Exp Brain Res 62:541-548.

Cruz JC, Tseng HC, Goldman JA, Shih H, Tsai LH (2003) Aberrant Cdk5 activation by $\mathrm{p} 25$ triggers pathological events leading to neurodegeneration and neurofibrillary tangles. Neuron 40:471-483.

de Silva HV, Harmony JA, Stuart WD, Gil CM, Robbins J (1990) Apolipoprotein J: structure and tissue distribution. Biochemistry 29:5380-5389.

Eisener-Dorman AF, Lawrence DA, Bolivar VJ (2009) Cautionary insights on knockout mouse studies: the gene or not the gene? Brain Behav Immun 23:318-324.

Fischer A, Sananbenesi F, Pang PT, Lu B, Tsai LH (2005) Opposing roles of transient and prolonged expression of p25 in synaptic plasticity and hippocampus-dependent memory. Neuron 48:825-838.

Forni PE, Scuoppo C, Imayoshi I, Taulli R, Dastrù W, Sala V, Betz UA, Muzzi P, Martinuzzi D, Vercelli AE, Kageyama R, Ponzetto C (2006) High levels of Cre expression in neuronal progenitors cause defects in brain development leading to microencephaly and hydrocephaly. J Neurosci 26:9593-9602.

Franklin KBJ, Paxinos G (2008) The mouse brain in stereotaxic coordinates, 3rd edition. Boston: Academic.

Furth PA, St Onge L, Böger H, Gruss P, Gossen M, Kistner A, Bujard H, Hennighausen L (1994) Temporal control of gene expression in transgenic mice by a tetracycline-responsive promoter. Proc Natl Acad Sci U S A 91:9302-9306.

Goodrich JA, Hoey T, Thut CJ, Admon A, Tjian R (1993) Drosophila TAFII40 interacts with both a VP16 activation domain and the basal transcription factor TFIIB. Cell 75:519-530.

Gossen M, Bujard H (1992) Tight control of gene expression in mammalian cells by tetracycline-responsive promoters. Proc Natl Acad Sci U S A 89:5547-5551.

Götz J, Chen F, Barmettler R, Nitsch RM (2001) Tau filament formation in transgenic mice expressing P301L tau. J Biol Chem 276:529-534. 
Harold D, Abraham R, Hollingworth P, Sims R, Gerrish A, Hamshere ML, Pahwa JS, Moskvina V, Dowzell K, Williams A, Jones N, Thomas C, Stretton A, Morgan AR, Lovestone S, Powell J, Proitsi P, Lupton MK, Brayne C, Rubinsztein DC, et al. (2009) Genome-wide association study identifies variants at CLU and PICALM associated with Alzheimer's disease. Nat Genet 41:1088-1093.

Higashi AY, Ikawa T, Muramatsu M, Economides AN, Niwa A, Okuda T, Murphy AJ, Rojas J, Heike T, Nakahata T, Kawamoto H, Kita T, Yanagita M (2009) Direct hematological toxicity and illegitimate chromosomal recombination caused by the systemic activation of CreERT2. J Immunol 182:5633-5640.

Imayoshi I, Sakamoto M, Ohtsuka T, Takao K, Miyakawa T, Yamaguchi M, Mori K, Ikeda T, Itohara S, Kageyama R (2008) Roles of continuous neurogenesis in the structural and functional integrity of the adult forebrain. Nat Neurosci 11:1153-1161.

Irizarry MC, McNamara M, Fedorchak K, Hsiao K, Hyman BT (1997a) APPSw transgenic mice develop age-related A beta deposits and neuropil abnormalities, but no neuronal loss in CA1. J Neuropathol Exp Neurol 56:965-973.

Irizarry MC, Soriano F, McNamara M, Page KJ, Schenk D, Games D, Hyman BT (1997b) Abeta deposition is associated with neuropil changes, but not with overt neuronal loss in the human amyloid precursor protein V717F (PDAPP) transgenic mouse. J Neurosci 17:7053-7059.

Jankowsky JL, Slunt HH, Gonzales V, Savonenko AV, Wen JC, Jenkins NA, Copeland NG, Younkin LH, Lester HA, Younkin SG, Borchelt DR (2005) Persistent amyloidosis following suppression of Abeta production in a transgenic model of Alzheimer disease. PLoS Med 2:e355.

Kempermann G, Gast D, Kronenberg G, Yamaguchi M, Gage FH (2003) Early determination and long-term persistence of adult-generated new neurons in the hippocampus of mice. Development 130:391-399.

Krestel HE, Mayford M, Seeburg PH, Sprengel R (2001) A GFP-equipped bidirectional expression module well suited for monitoring tetracyclineregulated gene expression in mouse. Nucleic Acids Res 29:E39.

Lee JY, Ristow M, Lin X, White MF, Magnuson MA, Hennighausen L (2006) RIP-Cre revisited, evidence for impairments of pancreatic beta-cell function. J Biol Chem 281:2649-2653.

Lewis J, McGowan E, Rockwood J, Melrose H, Nacharaju P, Van Slegtenhorst M, Gwinn-Hardy K, Paul Murphy M, Baker M, Yu X, Duff K, Hardy J, Corral A, Lin WL, Yen SH, Dickson DW, Davies P, Hutton M (2000) Neurofibrillary tangles, amyotrophy and progressive motor disturbance in mice expressing mutant (P301L) tau protein. Nat Genet 25:402-405.

Lin X, Parisiadou L, Gu XL, Wang L, Shim H, Sun L, Xie C, Long CX, Yang WJ, Ding J, Chen ZZ, Gallant PE, Tao-Cheng JH, Rudow G, Troncoso JC, Liu Z, Li Z, Cai H (2009) Leucine-rich repeat kinase 2 regulates the progression of neuropathology induced by Parkinson's-disease-related mutant alpha-synuclein. Neuron 64:807-827.

Ljungberg MC, Ali YO, Zhu J, Wu CS, Oka K, Zhai RG, Lu HC (2012) CREB-activity and nmnat2 transcription are down-regulated prior to neurodegeneration, while NMNAT2 over-expression is neuroprotective, in a mouse model of human tauopathy. Hum Mol Genet 21:251-267.

Lyon MF, Ogunkolade BW, Brown MC, Atherton DJ, Perry VH (1993) A gene affecting Wallerian nerve degeneration maps distally on mouse chromosome 4. Proc Natl Acad Sci U S A 90:9717-9720.

Manichaikul A, Dupuis J, Sen S, Broman KW (2006) Poor performance of bootstrap confidence intervals for the location of a quantitative trait locus. Genetics 174:481-489.

Mayford M, Bach ME, Huang YY, Wang L, Hawkins RD, Kandel ER (1996) Control of memory formation through regulated expression of a CaMKII transgene. Science 274:1678-1683.

McCloskey DT, Turnbull L, Swigart PM, Zambon AC, Turcato S, Joho S, Grossman W, Conklin BR, Simpson PC, Baker AJ (2005) Cardiac transgenesis with the tetracycline transactivator changes myocardial function and gene expression. Physiol Genomics 22:118-126.

McKinney BC, Schneider JS, Schafer GL, Lowing JL, Mohan S, Zhao MX, Heng MY, Albin RL, Seasholtz AF, Akil H, Murphy GG (2008) Decreased locomotor activity in mice expressing tTA under control of the CaMKII alpha promoter. Genes Brain Behav 7:203-213.

Moran JL, Bolton AD, Tran PV, Brown A, Dwyer ND, Manning DK, Bjork BC, Li C, Montgomery K, Siepka SM, Vitaterna MH, Takahashi JS, Wiltshire T, Kwiatkowski DJ, Kucherlapati R, Beier DR (2006) Utilization of a whole genome SNP panel for efficient genetic mapping in the mouse. Genome Res 16:436-440.
Morimoto M, Kopan R (2009) rtTA toxicity limits the usefulness of the SP-C-rtTA transgenic mouse. Dev Biol 325:171-178.

Muyllaert D, Terwel D, Kremer A, Sennvik K, Borghgraef P, Devijver H, Dewachter I, Van Leuven F (2008) Neurodegeneration and neuroinflammation in cdk5/p25-inducible mice: a model for hippocampal sclerosis and neocortical degeneration. Am J Pathol 172:470-485.

Nagy A (2003) Manipulating the mouse embryo: a laboratory manual, 3rd edition. Cold Spring Harbor, NY: Cold Spring Harbor Laboratory.

Naiche LA, Papaioannou VE (2007) Cre activity causes widespread apoptosis and lethal anemia during embryonic development. Genesis 45:768-775.

Owen EH, Logue SF, Rasmussen DL, Wehner JM (1997) Assessment of learning by the Morris water task and fear conditioning in inbred mouse strains and F1 hybrids: implications of genetic background for single gene mutations and quantitative trait loci analyses. Neuroscience 80:1087-1099.

Pletnikov MV, Ayhan Y, Nikolskaia O, Xu Y, Ovanesov MV, Huang H, Mori S, Moran TH, Ross CA (2008) Inducible expression of mutant human DISC1 in mice is associated with brain and behavioral abnormalities reminiscent of schizophrenia. Mol Psychiatry 13:173-186.

Ramsden M, Kotilinek L, Forster C, Paulson J, McGowan E, SantaCruz K, Guimaraes A, Yue M, Lewis J, Carlson G, Hutton M, Ashe KH (2005) Age-dependent neurofibrillary tangle formation, neuron loss, and memory impairment in a mouse model of human tauopathy (P301L). J Neurosci 25:10637-10647.

Robertson A, Perea J, Tolmachova T, Thomas PK, Huxley C (2002) Effects of mouse strain, position of integration and tetracycline analogue on the tetracycline conditional system in transgenic mice. Gene 282:65-74.

Rodgers SP, Born HA, Das P, Jankowsky JL (2012) Transgenic APP expression during postnatal development causes persistent locomotor hyperactivity in the adult. Mol Neurodegener 7:28.

Sadowski I, Ma J, Triezenberg S, Ptashne M (1988) GAL4-VP16 is an unusually potent transcriptional activator. Nature 335:563-564.

Santacruz K, Lewis J, Spires T, Paulson J, Kotilinek L, Ingelsson M, Guimaraes A, DeTure M, Ramsden M, McGowan E, Forster C, Yue M, Orne J, Janus C, Mariash A, Kuskowski M, Hyman B, Hutton M, Ashe KH (2005) Tau suppression in a neurodegenerative mouse model improves memory function. Science 309:476-481.

Schmidt EE, Taylor DS, Prigge JR, Barnett S, Capecchi MR (2000) Illegitimate Cre-dependent chromosome rearrangements in transgenic mouse spermatids. Proc Natl Acad Sci U S A 97:13702-13707.

Seshadri S, Fitzpatrick AL, Ikram MA, DeStefano AL, Gudnason V, Boada M, Bis JC, Smith AV, Carassquillo MM, Lambert JC, Harold D, Schrijvers EM, Ramirez-Lorca R, Debette S, Longstreth WT Jr, Janssens AC, Pankratz VS, Dartigues JF, Hollingworth P, Aspelund T, et al. (2010) Genome-wide analysis of genetic loci associated with Alzheimer disease. JAMA 303:1832-1840.

Sisson TH, Hansen JM, Shah M, Hanson KE, Du M, Ling T, Simon RH, Christensen PJ (2006) Expression of the reverse tetracyclinetransactivator gene causes emphysema-like changes in mice. Am J Respir Cell Mol Biol 34:552-560.

Spyropoulos DD, Bartel FO, Higuchi T, Deguchi T, Ogawa M, Watson DK (2003) Marker-assisted study of genetic background and genetargeted locus modifiers in lymphopoietic phenotypes. Anticancer Res 23:2015-2026.

Tremblay P, Meiner Z, Galou M, Heinrich C, Petromilli C, Lisse T, Cayetano J, Torchia M, Mobley W, Bujard H, DeArmond SJ, Prusiner SB (1998) Doxycycline control of prion protein transgene expression modulates prion disease in mice. Proc Natl Acad Sci U S A 95:12580-12585.

Wang L, Xie C, Greggio E, Parisiadou L, Shim H, Sun L, Chandran J, Lin X, Lai C, Yang WJ, Moore DJ, Dawson TM, Dawson VL, Chiosis G, Cookson MR, Cai H (2008) The chaperone activity of heat shock protein 90 is critical for maintaining the stability of leucine-rich repeat kinase 2. J Neurosci 28:3384-3391.

Wilson AC, Freiman RN, Goto H, Nishimoto T, Herr W (1997) VP16 targets an amino-terminal domain of HCF involved in cell cycle progression. Mol Cell Biol 17:6139-6146.

Yamamoto A, Lucas JJ, Hen R (2000) Reversal of neuropathology and motor dysfunction in a conditional model of Huntington's disease. Cell 101:57-66.

Zhou H, Huang C, Yang M, Landel CP, Xia PY, Liu YJ, Xia XG (2009) Developing tTA transgenic rats for inducible and reversible gene expression. Int J Biol Sci 5:171-181. 